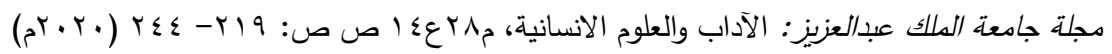

$$
\begin{aligned}
& \text { DOI:10.4197/Art.28-14.6 }
\end{aligned}
$$

الرفاهية النفسية وعلاقتها بإدارة الذات لدى عينة من الطالبات ذوات الإعاقة بجامعة الملك عبد العزيز

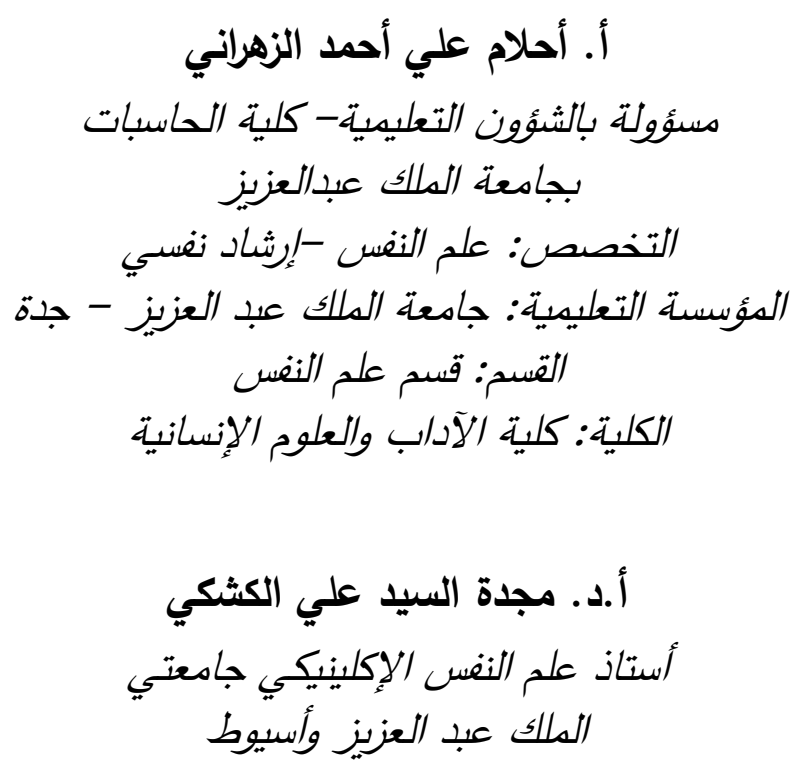

مستخلص. هدفت الدراسة الحالية إلى التعرف على الرفاهية النفسية وعلاقتها بإدارة الذات لدى عينة من الطالبات

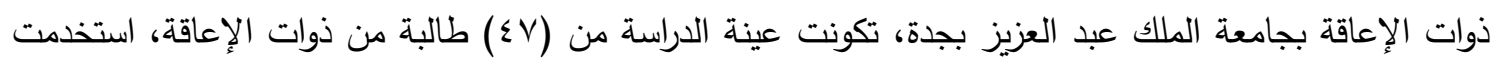
الباحثة المنهج الوصفي الارتباطي والمقارن، كما استخدمت المقاييس التالية: مقياس الرفاهية النفسية لرايف

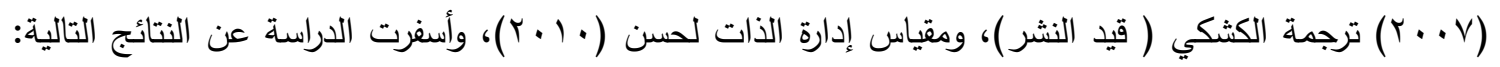

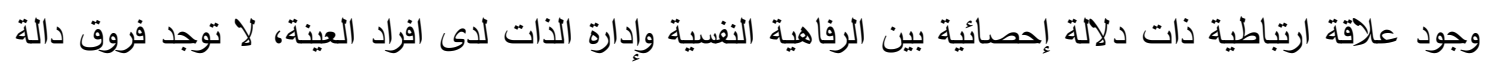

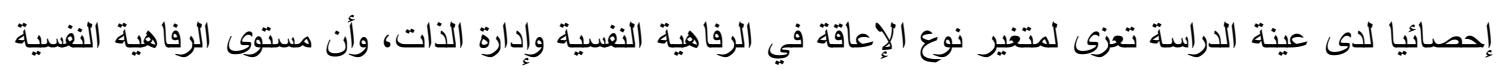
ومستوى إدارة الذات لاى أفراد العينة مرتفع، وفي ضوء هذه لدئه النتائج تم وضع عدئ عدد من التوصيات. كلمات مفتاحية: الرفاهية النفية، إدارة الذات، الطلبة ذوي الإعاقة. 
الفرد لذاته تؤثر على نظرته لنفسه وللعالم المحيط به مهما كانت المتاعب والضغوط التي يمر بها لهردئه (هادي، 9 1 • بـ). وتكمن إدارة الذات في قدرة الفرد على توجيه مشاعره

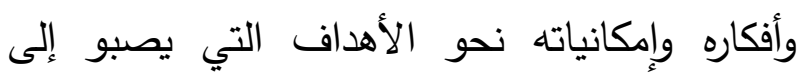
تحقيقها. فالذات هي ما يملكه الفرد من مشاعر الفراته وأفكار وإمكانات وقدرات، وإدارتها تعني استغلال هله ذلك كله الاستغلال الأمثل في تحقيق الأهداف وافتان

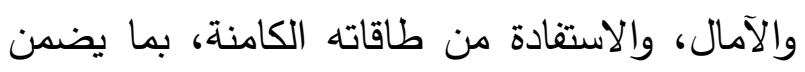

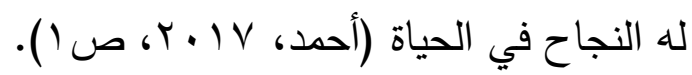
وإن إدارة الفرد لذاته بشكل واعي يحقق له اله التقدم

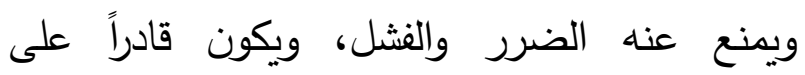
الاستفادة من تجارب الحياة الناجحة التي تجعله ذو ولهون

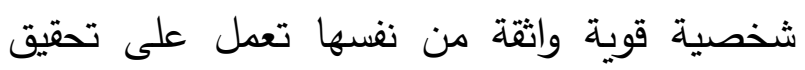

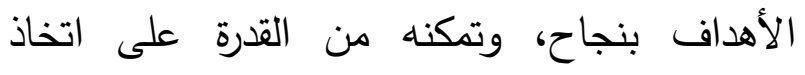
القرارات والقدرة على إدارة الانفعالات مما يحقق له له لهن

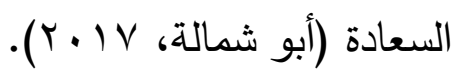
وأيدت ذلك العديد من الدراسات منها دراسة ياسين

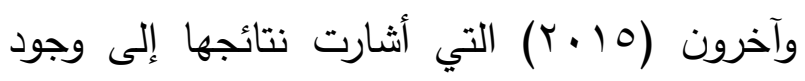
علاقة طردية بين إدارة الذات والسعادة، فكلما نجح الفرد في إدارة ذاته أدى ذلك إلى شعوره بالسعادة

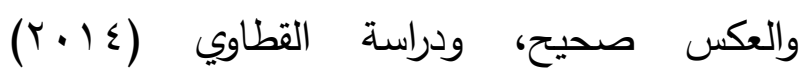

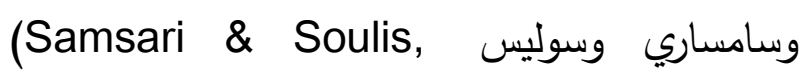
(2019 التي أسفرت نتائجها عن وجود علاقة إيجابية بين الرفاهية النفسية والسعادة وبين الكفاءة

\section{المقدمة}

حظي الأفراد من فئة ذوي الاحتياجات الخاصة

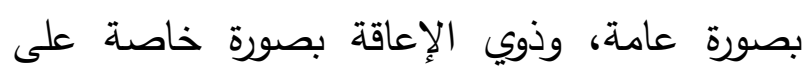
اهتمام متزايد في السنوات الأخيرة، فقد أولت المملكة

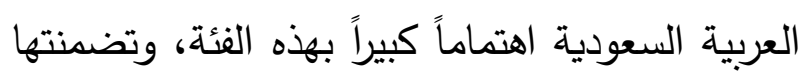
في خططها الوطنية تماشياً مع رؤية المملكة

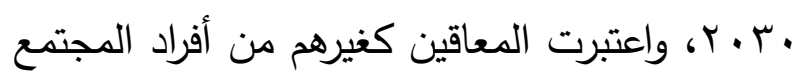

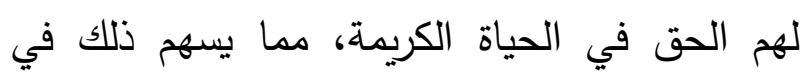
تخفيف الضغوط النفسية لهذا الفئة والثعور بالرضا لهاه وتحقيق أعلى قدر من الرفاهية النفسية التي تعتبر قمة مطالب الحياة الإنسانية. فالرفاهية النفسية تأتي في صدارة مفاهيم علم النفس الأنسانيه الإيجابي الذي أصبح نموه وازدهاره ملحوظاً في الآونة الأخيرة، حيث يطرح هذا العلم العديد من من لهن الهفاهيم النفسية الإيجابية التي تعين الإنسان على الإنى

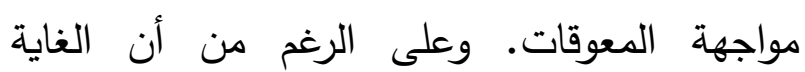
الأساسية لعلم النفس هي مساعدة الفرد أن يحيا الحياة الطيبة التي يشعر فيها بالسعادة، فقد تجاهل علماء النفس لسنوات طويلة المشاعر الإيجابية للشخصية وظلت الانفعالات السلبية مثل: القلق، والاكتئاب، والضغوط النفسية، والتشاؤم الأكثر تتاولاً

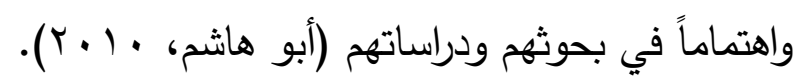
وتعتبر الرفاهية النفسية أحد المؤشرات الهامة للرضا واتها عن الحياة، فهي الغاية المنشودة التي يسعى الإنسان إلى الوصول إليها، والتي يؤدي تحقيقها إلى شعور

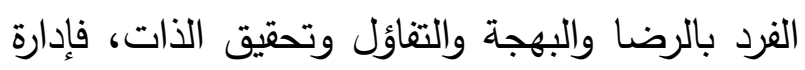


"ما العلاقة بين الرفاهية النفسية وإدارة الذات لاى عينة من الطالبات ذوات الإعاقة بجامعة الملك عبد لماته

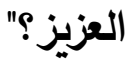

وينبثق من هذا التساؤل الرئيس الأسئلة الفرعية

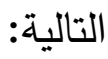

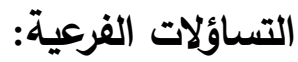

• ما مستوى الرفاهية النفسية لدى عينة الدراسة؟

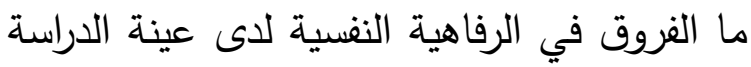
وفقاً لنوع الإعاقة (الجسدية- الحسية)؟ ما مستوى إدارة الذات لدى عينة الدراسة؟ ما ما الفروق في إدارة الذات لاى عينة الدراسة وفقاً لنوع الإعاقة (الجسدية- الحسية)؟

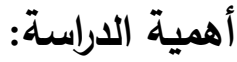
تتضح أهمية الدراسة الحالية من الناحيتين النظرية والتطبيقية كالتالي: م الأهمية النظرية - عدم توافر البحوث والدراسات التي تتاولت موضوع الرفاهية النفسية وإدارة الذات لدى الطالبات ذوات الإعاقة _في حدود علم الباحثة_ وخصوصاً في البيئة السعودية. - مواكبة الاتجاه الجديد للدراسات الحديثة التي لماتي أصبحت تركز على الجوانب الإيجابية للشخصية والموضوعات التي تتتمي إلى مجال علم النفس الإيجابي.

- يتواكب موضوع الدراسة مع روئية المملكة •r.r التي تعكس الاهتمام الكبير بجودة الحياة
ولم يحظ موضوع الدراسة الحالية بالاهتمام الكافي

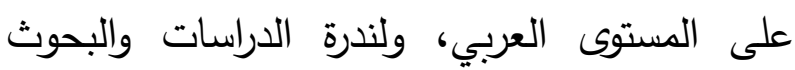
العلمية في موضوع الدراسة وخاصة لدى فئة ذوات الإعاقة، الأمر الذي حملنا على محاولة التعرف على العلاقة بين الرفاهية النفسية وإدارة الذات لدى الدى عينة من الطالبات ذوات الإعاقة بجامعة الملك عبد

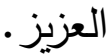
مشكلة الدراسة: تلعب ظروف الحياة اليومية الراهنة التي تعيشها الطالبات من فئة ذوات الإعاقة، سواء كانت اجتماعية، أو نفية، أو صحية دوراً في استقرارهن الفكري والنفسي وتحصيلهن الأكاديمي، وهذا بدوره يشكل تحدياً أمام ذواتهن وطرق وإدارتهن لها وإيجاد الوسائل والأساليب التي تخفف من آثاره. فلا عجب لتبان

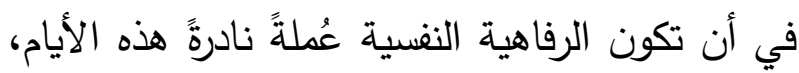
فالرفاهية النفسية تعكس الأداء النفسي الإيجابي، فهي تحدد علاقة الفرد بذاته من تقبلها وتفردها والوعي بها بما يحقق استقلاليتها رغم تمتعه بعلاقات

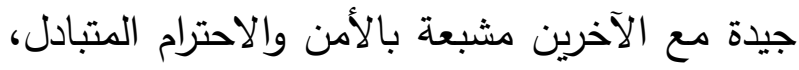
ساعياً لتحقيق أهداف ومقاصد حياتية يتبناها من خلال استغلاله لكافة الفرص البيئية وتغلبه على ما يواجهه من معوقات، بما يحقق له التقدم والاستمرارية

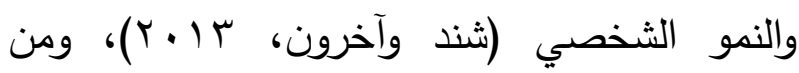
خلال ما سبق تمحورت مشكلة الدراسة الحالية في

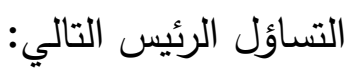




$$
\text { أحلام علي أحمد الزهراني و مجدة السيد علي الكثكي }
$$

• الفروق في إدارة الذات لاى عينة من الطالبات

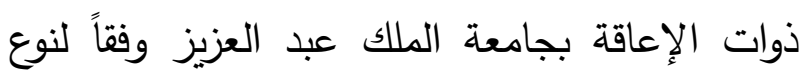

$$
\text { الإعاقة (الجسدية- الحسية) }
$$

مصطلحات الادراسة:

اشتملت الدراسة الحالية على عدد من المصطلحات وهي الرفاهية النفسية وإدارة الذات وذوي الإعاقة وفيما يلي التعريف العلمي والإجرائي لكل مصطلح منها:

أولاً: الرفاهية النفسية:

يعد مفهوم الرفاهية النفسية من المفاهيم الحديثة نسبياً، فقد اختلفت ترجمته إلى اللغة العربية فبعضهم لمهاهيه يعده مرادفاً للسعادة، كما تمت ترجمته إلى الرضا عن الحياة، وبعضهم يراه مرادفاً للصحة النفسية،

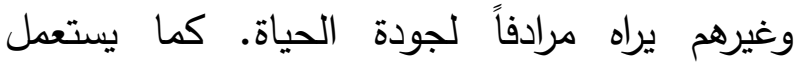
الباحثون عدة مفاهيم أخرى منها الهناء الشخصي، يراه هردئ

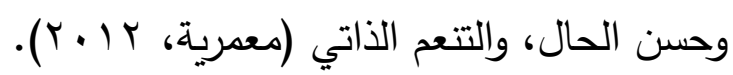
التعريف العلمي للرفاهية النفسية: عرفت "بأنها تمتع الفرد بالصحة النفسية الجيدة والإيجابية والقدرة على متابعة الأهداف ذات المغزى بـى لئه

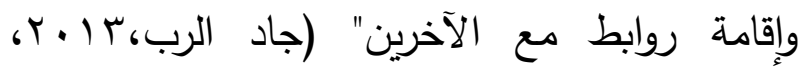

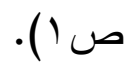

كما عرفت بأنها مفهوم يشير إلى كيفية تقييم الفرد

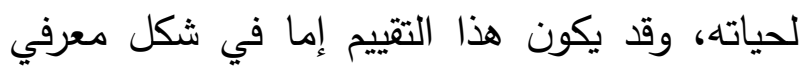
إدراكي حيث التقييم قائم على معلومات عن حياة الفرد، أي أحكام تقديرية حول رضا الفرد عن حياته ككل، أو في شكل تقدير الفاعلية وهو تقييم هادئ
والاهتمام بإنسان الوطن والذي يتضمن فئة ذوي الإعاقة، التي أولتهم المملكة في هذه الرؤية مزيداً من الاهتمام والتطوير في جميع المجالات. - إثراء للمكتبة العربية والسعودية في مجال متغيرات

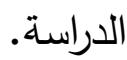

\section{الناحية التطبيقية}

- الاستفادة من نتائج الدراسة الحالية في تقديم برامج تدريبية أو ارشادية وتعميمها على مراكز التأهيل ومراكز ذوي الاحتياجات الخاصة لمساعدة الطلبة من ذوي الإعاقة على تحقيق أعلى قدر مدكن من الرفاهية النفسية وبرامج لتنمية مهارة إدارة الذات لاتهي

لايهم. - تزويد وزارة الإعلام بنتائج الدراسة لمناقشتها في برامجها. أهداف الدراسة: تتمثل أهداف الدراسة في التعرف على:

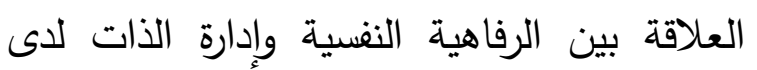
عينة من الطالبات ذوات الإعاقة بجامعة الملك عبد

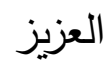
• مستوى الرفاهية النفسية لاى عينة من الطالبات ذوات الإعاقة بجامعة الملك عبد العزيز

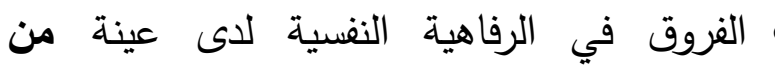
الطالبات ذوات الإعاقة بجامعة الملك عبد العزيز وفقاً لنوع الإعاقة (الجسدية- الحسية) • مستوى إدارة الذات لدى عينة من الطالبات ذوات الات الإعاقة بجامعة الملك عبدالعزيز 
ورؤية واضحة توجه أفعاله وتصرفاته وسلوكياته مع المثابرة والإصرار على تحقيق أهدافه.

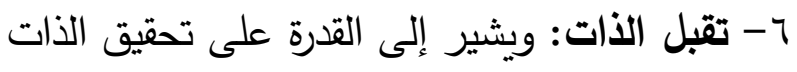

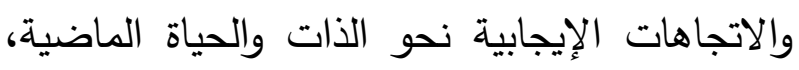
وتقبل المظاهر المختلفة للذات بما فيها من جوانب والبهابل إيجابية وأخرى سلبية. وتقاس بالدرجة التي يحصل عليها أفراد عينة الدراسة

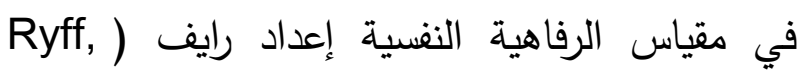
2007) وترجمة الكشكي ( قيد النشر). ثانياً: إدارة الذات: ويعد مفهوم إدارة الذات مرادفاً لمفهوم التنظيم الذاتي ومفهوم الكفاءة الذاتية. التعريف العلمي لإدارة الذات: عرفت إدارة الذات بأنها: "معرفة الثخص لقدراته ومهاراته الذاتية، والاستخدام الأمثل لهذه القدرات

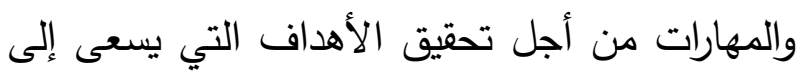

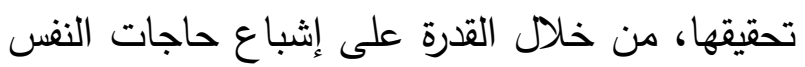
الأساسية لخلق حالة من التوازن في الحياة بين الحاجات والرغبات والأهداف والأولويات" (العواودة،

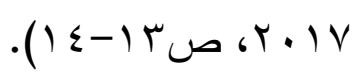

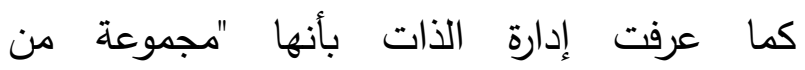

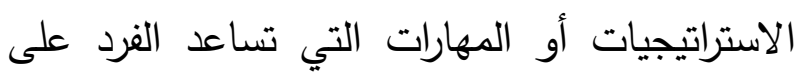

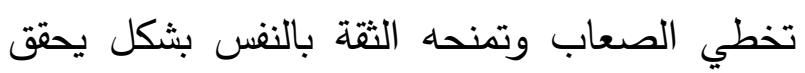

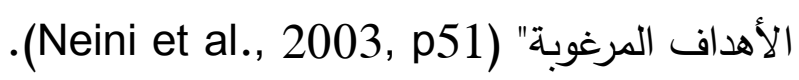

يسترشد بالعواطف والمشاعر التي تتكرر لدى الفرد

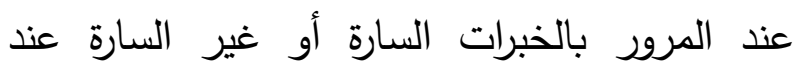
التفاعل مع الحياة (Maaulot, et al., 2015). التعريف الإجرائي للرفاهية النفسية:

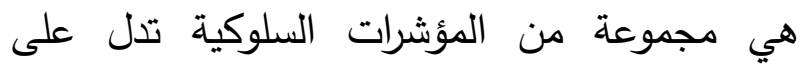
ارتفاع مستويات رضا الفرد عن حياته بشكل عام، وحدتها رايف وسينجر (Ryff \& Singer, 2008) في ستة أبعاد وهي: رابف ونينج ا-الاستقلالية: ويشير إلى استقلالية الفرد وقدرته

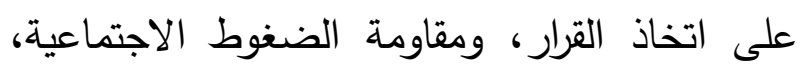

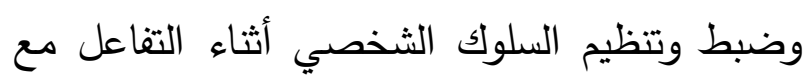

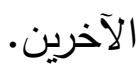
r-التمكن البيئي: قدرة الفرد على التمكن من تتظيم

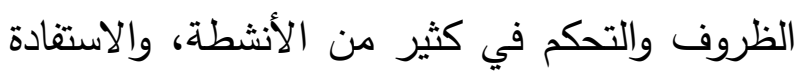
بطريقة فعالة من ظروف من الظروف المحيطة، وتوفير البيئة المناسبة، والمرونة الشخصية. ب-النمو الثخصي: قدرة الفرد على تتمية وتطوير

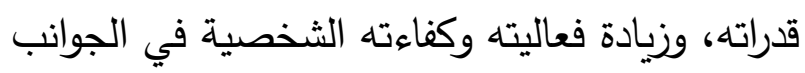
المختلفة، والشعور بالتفاؤل. ع -العلاقات الإيجابية: قدرة الفرد على تكوين وإقامة

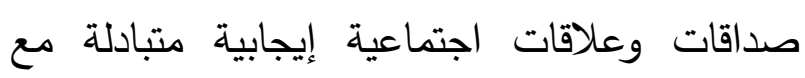
الآخرين على أساس من: الود، والتعاطف، والثقة

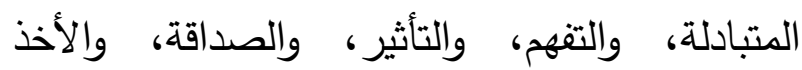
والعطاء. ه-الهدف في الحياة: قدرة الفرد على تحديد أهدافه

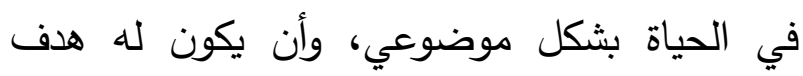




$$
\text { أحلام علي أحمد الزهراني و مجدة السيد علي الكثكي }
$$

ثالثاً: ذوي الإعاقة: التعريف العلمي لذوي الإعاقة: "هم أولئك الأفراد الذين يختلفون عن الأفراد العاديين في بعض السمات الشخصية سواء كانت جسمية أو حسية أو عقلية سواء كانت هذه الاختلافات فطرية أو مكتسبة وبالتالي يحتاجون إلى رعاية خاصة تختلف عن تلك التي تقدم للأفراد العاديين" (راشد

$$
\text { وأحمد، } 0 \text { ( • r، صنمر). }
$$

التعريف الإجرائي لذوات الإعاقة:

عرفت الباحثة ذوات الإعاقة بأنهم الطالبات من جامعة الملك عبد العزيز اللاتي يعانون من ضعف أو نقص في قدراتهن نتيجة لقصور إما جسدي أو حسي، مما يجعلهن يختلفن عن أقرانهن ويكن في حاجة إلى رعاية وتكفل خاص. وستتناول الباحثة نوعين من أنواع الإعاقة وهي

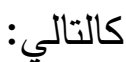
- الإعاقة الجسدية: وهي خلل في الوظائف الجسدية لطرف أو أكثر نتيجة لأسباب مختلفة كحادث معين، أو إصابة بمرض معين. - الإعاقة الحسية: وهي تتمثل في ثلاث أنواع من الإعاقة وهي (السدعية - البصرية- النطقية) وقد تكون الإعاقة بشكل جزئي أو كلي. الاراسات السابقة نظراً لندرة الدراسات العربية والأجنبية التي تتاولت بشكل مباشر الرفاهية النفسية وإدارة الذات لدى ذوي الإعاقة، لذلك قامت الباحثة بالتركيز على دراسات
التعريف الإجرائي لإدارة الذات:

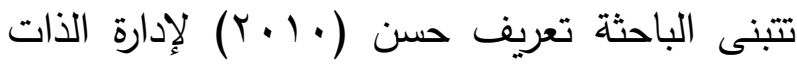
"بأنها قدرة الشخص على مراقبة سلوكه مستخدماً أنسب الطرق والوسائل التي تساعد على الاستفادة القصوى من وقته لتحقيق أهدافه، وإيجاد التوازن في حياته مابين الواجبات والرغبات والأهداف وتتحدد في الأبعاد التالية: أهداف الذات، والتخطيط للذات، والعلاقات مع الآخر، ورقابة وتقويم الذات

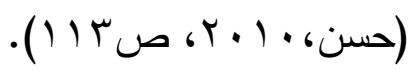

ويمكن تعريفها كالتالي: - اهداف الأات: تتمثل في وضع وتحديد الأهداف الواقعية مما يساعد على تحقيق نتائج مهمة في حياة

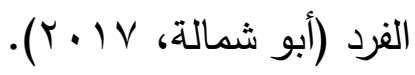
- التخطيط للذات: ويشمل تحديد الأهداف وترتيب الأوليات وطريقة التخطيط لتنفيذ المهام - العلاقات مع الآخر: وهي القدرة الفرد على التعامل والتفاعل مع الآخرين في أي مكان

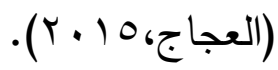
- مراقبة وتقويم الأتات: هي قدرة الأفراد على ملاحظة وتوجيه سلوكهم بشكل منتظم، وتحديد مدى ظهور او عدم ظهور السلوك المستهدف (مطر، $\cdot(r \cdot) \varepsilon$ وتقاس بالدرجة التي تحصل عليها الطالبة في مقياس إدارة الذات إعداد (حسن، . • ب). 
متعددة الأبعاد، وأوضحت النتائج أن الرضا عن الحياة للطلبة ذوي الإعاقة الحركية مرتفع.

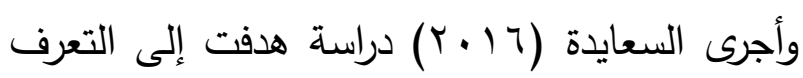
إلى مستوى جودة الحياة للمعاقين سمعيا الملتحقين بمراكز التربية الخاصة في محافظة البلقاء، وقد تكونت عينة الدراسة من (؟^) طالبا وطالبه يعانون من الإعاقة السمعية. وقد استخدم الباحث المنهج الوصفي في الدراسة، كما استخدم مقياس جودة الحياة للمعاقين سمعيا. حيث أشارت نتائج الدراسة إلى أن مستوى جودة الحياة لدى الطلبة المعاقين سمعيا كان متوسطا.

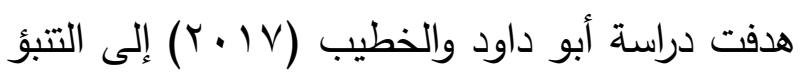
بالعلاقة بين الرضا عن الحياة وكل من مهارات تقرير المصير والأمل لدى المراهقين ذوي الإعاقة (البصرية، صعوبات التعلم، الحركية) في الاردن، وتكونت العينة من (·9) مراهق ومراهقة، واستخدم الباحث الأدوات التالية: مقياس الرضا عن الحياة ومقياس تقرير المصير ومقياس الأمل، كما استخدم المنهج الوصفي الارتباطي، وتوصلت نتائج الدراسة إلى أن مستوى الرضا عن الحياة لدى عينة الدراسة

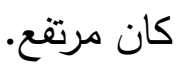
• دراسات تناولت إدارة الذات هربع إن

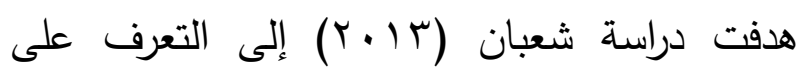
العلاقة بين التنظيم الذاتي وتقدير الذات لدى عينة من ذوي الإعاقة البصرية، وتكونت العينة من ( (7) طالباً وطالبة من ذوي الإعاقة البصرية في معهد
تتاولت مرادفات وأبعاد كلاً من الرفاهية النفسية وإدارة الذات لدى ذوي الإعاقة، وقد تم تصنيف هذه الدراسات في ثلاث محاور وهي: • دراسات تتاولت متغير الرفاهية النفسية. دراسات تناولت متغير إدارة الذات. دراسات سابقة تتاولت الرفاهية النفسية وإدارة

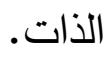
وفيما يلي سيتم استعراض بعضاً من الدراسات التي تم الاطلاع عليها في كل محور من هذه المحاور الثلاثة:

\section{دراسات تناولت الرفاهية النفسية:}

هدفت دراسة العوراني (10 • ( ) إلى تحديد مستوى مفهوم الذات والرضا عن الحياة لدى الطلبة ذوي الإعاقة البصرية والطلبة ذوي الإعاقة السمعية في

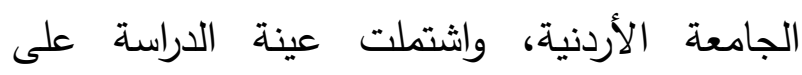
(0. (1) طالب وطالبة، وقد طبق الباحث الأدوات الآتية: مقياس تتسي لمفهوم الذات - مقياس الرضا عن الحياة، وأسفرت نتائج الدراسة أن مستوى الرضا عن الحياة كان مرتفعاً لدى عينة الدراسة. Awasthi et al., ) تناولت دراسة أواسذي وآخرون 2016) الرفاهية النفسية لدى الطلاب ذوي الإعاقة الحركية والطلاب العاديين، تكونت عينة الدراسة من

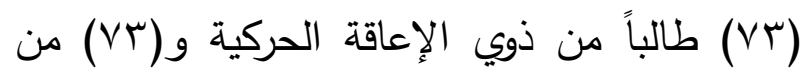
الطلاب العاديين في المدارس والجامعات في فاراناسي، تم استخدام مقياس الرضا عن الحياة 


$$
\text { أحلام علي أحمد الزهراني و مجدة السيد علي الكثكي }
$$

الوصفي، وأظهرت نتائج الدراسة وجود معامل ارتباط

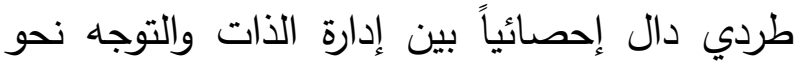
الحياة لدى أفراد عينة الدراسة، كما أوضحت نتائج الدراسة أن مستوى إدارة الذات لدى العينة كان الداء متوسطاً.

Sandjojo et al., ) وقام ساندجوجو وآخرون 2019) بدراسة هدفت إلى التعرف على مدى فعالية التدريب على إدارة الذات للأشخاص ذوي الإعاقات الذهنية الموجهة نحو العمل المستقل في الحياة اليومية، وكانت العينة مكونة من (V V) شخصًا من ذوي الإعاقات الذهنية، تم استخدام مقياس نوعية الحياة وبرنامج تدريبي لإدارة الذات، كما تم استخدام المنهج الوصفي، أشارت النتائج إلى تحقيق أهداف إدار الذات لتغطي مجموعة واسعة من الشؤون اليومية، وأسفرت النتائج بأنه لم تكن هناك تغييرات في السلوك النفسي المرضي ونوعية الحياة. دراسات سابقة تناولت الرفاهية النفسية وإدارة

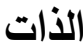

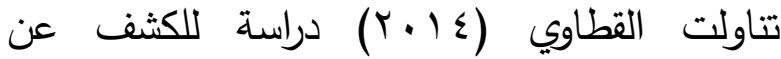
العلاقة بين الشعور بالسعادة وتتدير الذات والمساندة الاجتماعية والمستوى الاقتصادي للمعاقين سمعيا، وتم تطبيق الدراسة على عينة من الطلاب المعاقين

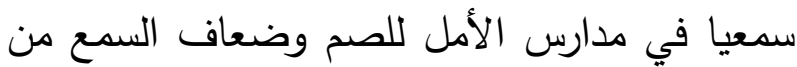
مدينة ميت غمر ومدينة الزقازيق بلغ عددها (.7 (1) طالب وطالبة، واستخدمت الباحثة الأدوات التالية

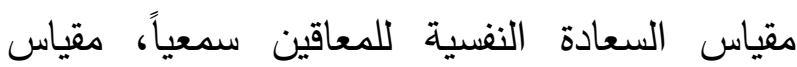

النور للمكفوفين في بمدينة شبين الكوم، وطبق عليهم مقياسين: مقياس التنظيم الذاتي لذوي الإعاقة البصرية ومقياس تقدير الذات لذوي الإعاقة البصرية، استخدم الباحث المنهج شبه التجريب، وأسفرت النتائج عن وجود ارتباطية إيجابية بين التتظيم الذاتي وتقدير الذات لدى أفراد العينة.

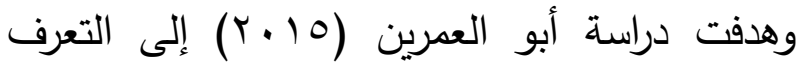
على مستوى مفهوم الذات واستراتيجيات التواصل الاجتماعي لدى الطلبة الصم في ضوء التقدم التقني، وتكونت العينة من (V•l) من الطلبة الصم في الجامعة الإسلامية بغزة، استخدم الباحث مقياسين: مقياس مفهوم الذات ومقياس التواصل الاجتماعي، كما استخدم الباحث المنهج الوصفي التحليلي، وأسفرت النتائج عن وجود ارتباطية بين مفهوم الذات واستراتيجيات التواصل الاجتماعي للى عينة الدراسة، وأن مستوى التواصل الاجتماعي لاى افراد

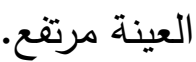
كما أجرى أبو شمالة (Y. V (Y) دراسة هدفت إلى معرفة هل يعتبر مفهوم إدارة الذات عاملاً وسيطاً بين الحساسية الانفعالية والتوجه نحو الحياة للطلبة الجامعيين من ذوي الإعاقة السمعية في الجامعة الإسلامية بغزة، وتكونت عينة الدراسة الفعلية من

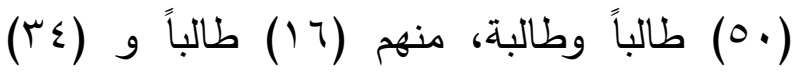
طالبة، واستخدم الباحث الأدوات الآتية: مقياس إدارة الذات، ومقياس الحساسية الانفعالية، ومقياس التوجه نحو الحياة، من إعداد الباحث، واستخدم المنهج 
للكفاءة الذاتية ، ومرونة الكفاءة الذاتية والرفاهية

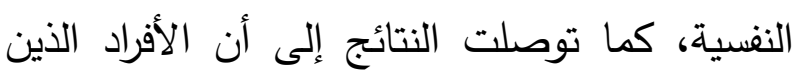

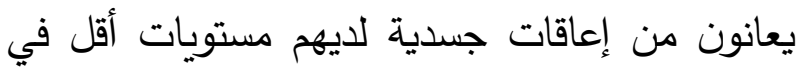

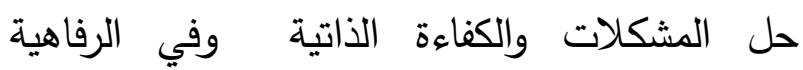

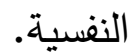

وهدفت دراسة أحمد (19 • (Y) إلى التعرف على العوامل الخمسة الكبرى للشخصية وعلاقتها بالسعادة النفية لاى عينة من الطلاب المعاقين بجامعة الفاشر، بمدينة الفاشر ولاية شمال دارفور، وللتأكد

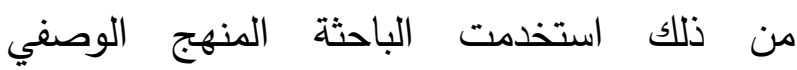

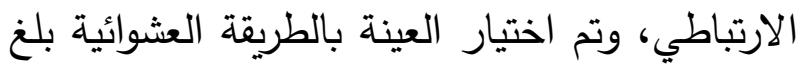

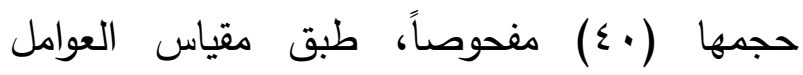

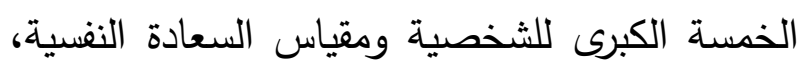
توصلت الدراسة إلى النتائج الآتية: تتسم درجة العوامل الخمسة الكبرى للشخصية بالارتفاع، كما لا لا لهابل توجد علاقة ارتباطية ذات دلالة إحصائية بين العوامل الخمسة الكبرى للثخصية والسعادة النفسية

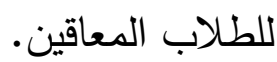
تعليق عام على الاراسات السابقة: - استفادت الدراسة الحالية من الدراسات السابقة في تحديد الأهداف، وحسن اختيار العينة، والوقوف التران

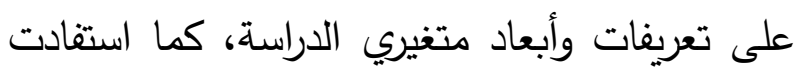
منها في تحديد مقياس الرفاهية النفسية ومقياس إدارة الذات التي سيتم استخدامهما، كما أنها ستعينها في لهيد تنسير النتائج.
المساندة الاجتماعية ، مقياس تقدير الذات، واستمارة المستوى الاقتصادي، واستخدمت الباحثة المنهج الوصفي، وتوصلت نتائج الدراسة إلى وجود ارتباط دال وموجب بين السعادة وكل من تقدير الذات، والمساندة الاجتماعية، والمستوى الاقتصادي.

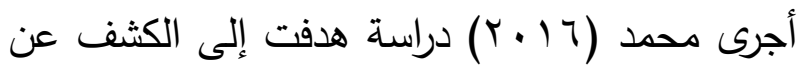
طبيعة العلاقة بين جودة الحياة لذوي الاعاقة السمعية وتشكيل هوية الانا والسلوك الاجتماعي

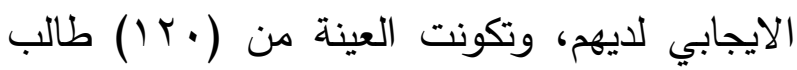

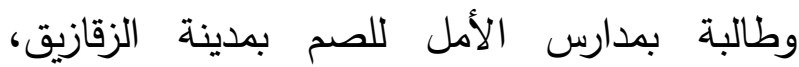
واستخدم الباحث الأدوات التالية: مقياس جودة الحياة لذوي الاعاقة السمعية ومقياس وظائف هوية الأنا ومقياس السلوك الاجتماعي الإيجابي، كما استخدم المنهج الوصفي الارتباطي، وتوصلت نتائج الدراسة إلى وجود علاقة ارتباطية بين السلوك الاجتماعي الاربي ولودي الايجابي وجودة الحياة لدي عينة الدراسة. Samsari \& ) وهدفت دراسة سامساري وسوليس وجناه (Soulis, 2019 إلى دراسة العلاقات بين حل المشكلات والكفاءة الذاتية ومرونة الكفاءة الذاتية والرفاهية النفسية والتمييز بين هذه العوامل بين الأشخاص الذين يعانون من إعاقات جسدية وبدونها، تكونت العينة من (10.1 ) شخصًا يعانون من إعاقات جسدية و (10.1 ) شخصًا بدون إعاقات في اليونان،

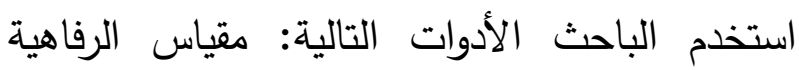
النفسية ومقياس توقعات الكفاءة الذاتية، أظهرت النتائج وجود ارتباطات إيجابية بين حل المشكلات 


$$
\text { أحلام علي أحمد الزهراني و مجدة السيد علي الكثكي }
$$

الارتباطي للتعرف على العلاقة بين الرفاهية النفسية وإدارة الذات لاى عينة الدراسة، واستخدم المنهج المقارن للوصول إلى الفروق بين طالبات ذوي

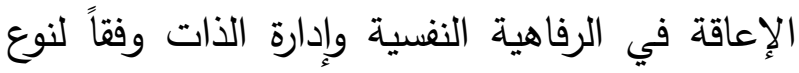
الإعاقة (الجسدية- الحسية). ب- مجتمع الاراسة:

تكون مجتمع الدراسة من جميع الطالبات ذوات الإعاقة (الجسدية- الحسية) في جامعة الملك عبد العزيز بجدة والبالغ عددهن (YOr) طالبة حسب الإبه احصائيات مركز ذوي الاحتياجات الخاصة بجامعة الملك عبد العزيز بجدة. ج-عينة الدراسة: تكونت عينة الدراسة من (₹₹) طالبة من الطالبات ذوات الإعاقة منهن (ع () طالبة من ذوات الإعاقة الجسدية، و(rr) طالبة من ذوات الإعاقة الحسية بجامعة الملك عبد العزيز بجدة في المدى العمري

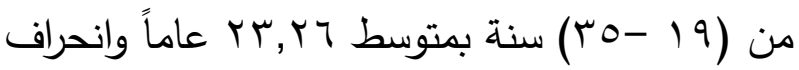
معياري مقدار ب,99 ب ، وكانت عينة عمدية تم اختيارهن بطريقة عشوائية بسيطة. د-أدوات الدراستة: من أجل تحقيق الأهداف وللتحقق من صحة الفروض تم استخدام أداتين هما: مقياس الرفاهية النفسية لرايف: ترجمة الكشكي

$$
\text { (قيد النشر) }
$$

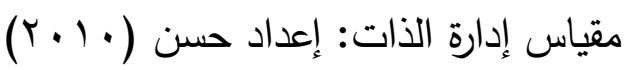
وفيما يلي وصف لهذين المقياسين:
- أجريت العديد من الدراسات العربية والعالمية حول الرفاهية النفسية وإدارة الذات ولكن كل متغير جاء

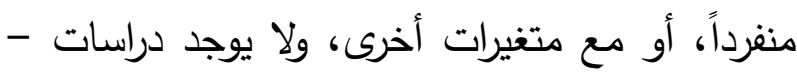
في حدود علم الباحثة- تتاولت العلاقة بين الرفاهية النفسية إدارة الذات لاى ذوي الإعاقة، وهذا ما يميز

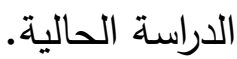
- ركزت جميع الدراسات السابقة على دراسة عينة من فئة ذوي الإعاقة مما يؤكد أهمية هذه الفئة. فروض الاراسة: من خلال أهداف الدراسة والدراسات السابقة التي تتاولت متغيراتها نستطيع صياغة فروض الدراسة كالتالي: - ت ت ت - توجد علاقة ارتباطية ذات دلالة إحصائية بين الرفاهية النفسية وإدارة الذات لدى عينة من الطالبات ذوات الإعاقة بجامعة الملك عبد العزيز - توجد فروق ذات دلالة إحصائية بين متوسطي درجات الرفاهية النفسية لدى عينة الدراسة تعزى لنوع دله الإعاقة (الجسدية- الحسية) توجد فروق ذات دلالة إحصائية بين متوسطي

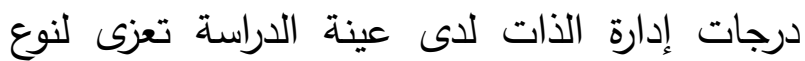
الإعاقة (الجسدية- الحسية) منهج الاراسة وإجراء/تها أ-منهج الدراسة: استخدمت الباحثة المنهج الوصفي الارتباطي

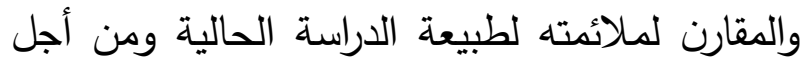
تحقيق أهدافها، حيث استخدم المنهج الوصفي 
الارتباط وكانت دالة إحصائياً عند ا ., . بين مقياس الرفاهية النفسية ومقياس الاستمتاع بالحياة

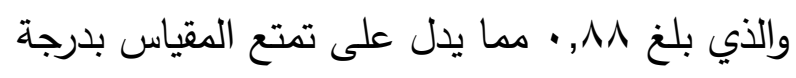
عالية من الصدق.

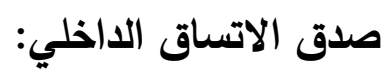
وتم التحقق منه بحساب قيم معاملات الاتباط لداط الفقرة

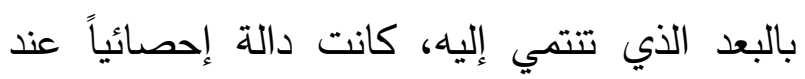

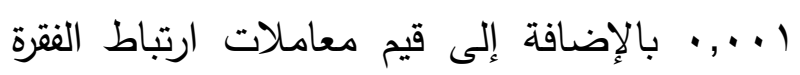
بالمقياس ككل، ومعاملات ارتباط كل بعد بالدرجة الكلية على المقياس، حيث تراوحت قيم معاملات الارتباط للفقرات مع البعد الذي تتنمي إليه ما بين

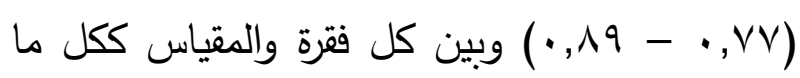
بين (1,07,--19, •)، بين الأبعاد والمقياس ككل

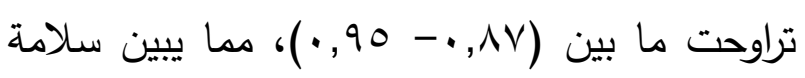
بناء المقياس وترابطه بما يسمح باستخدامه. ثبات المقياس: تم حساب الثبات بعدة طرق وهي ألفا كرونباخ وإعادة التطبيق والتجزئة النصفية، تراوحت معاملات ألفا

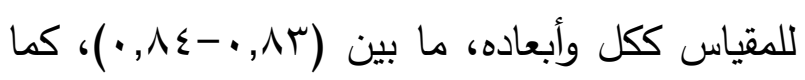
أن قيمة معامل ثبات الإعادة للمقياس ككل بلغت (بو, • · )، كما بلغ معامل الارتباط للتجزئة النصفية

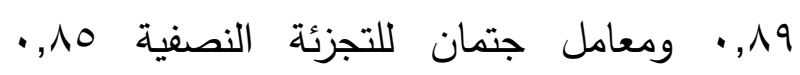

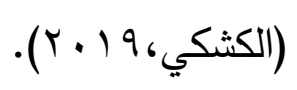

1- مقياس الرفاهية النفسية لرايف: ترجمة الكشكي ( قيد النشر)

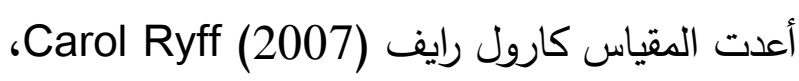
وقامت بترجمته الكشكي ( قيد النشر)، يتكون

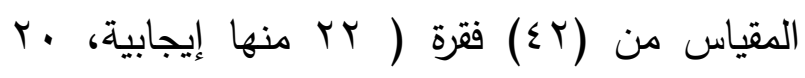

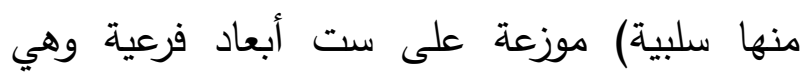
(الاستقلالية - التمكين البيئي- النمو الثخصية) العلاقات الإيجابية- الهدف من الحياة- تقبل التبل الذات)، أما من حيث بدائل الاستجابة فهي ست الإبت الت بدائل (غير موافق بشدة - غير موافق إلى حد ما - ماند

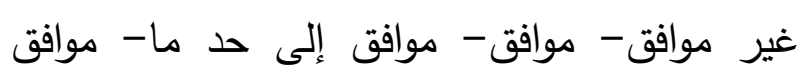
بشدة)، وقد أعطيت قيما للاستجابات على عبارات

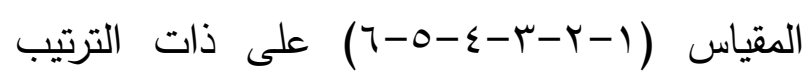

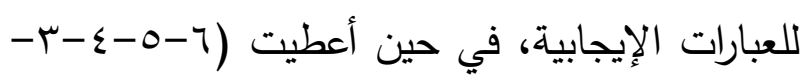

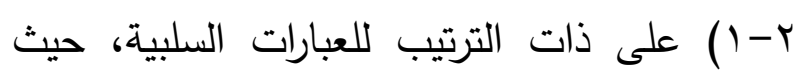
تشير ارتفاع الدرجة إلى ارتفاع مستوى الرفاهية النفسية

قامت الكثكي (قيد النشر) بالتحقق من الخصائص

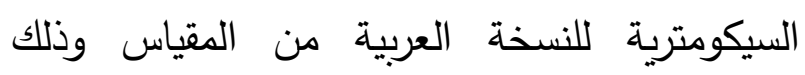

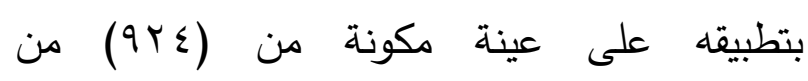
السعوديين، وتم التحقق من صدق وثبات المقياس كما يلي: صدق المقياس لـ تم التحقق من صدق المقياس بعدة طرق:

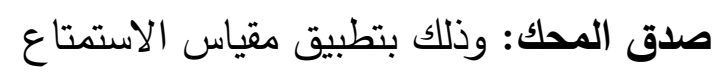
بالحياة على عينة التقنيين، ثم تم حساب معامل 


\section{التحقق من الثروط السيكومترية لمقياس الرفاهية الصدق:}

تم حساب الصدق وذلك من خلال:

صدق الاتساق الداخلي: وتم بحساب معامل ارتباط بيرسون بين كل من: درجة كل فقرة مع الدرجة الكلية

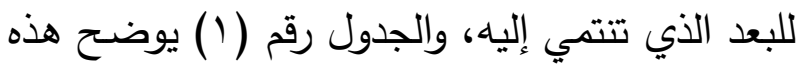

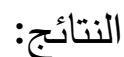

النفسية في الاراسة الحالية: للتحقق من الثروط السيكومترية للمقياس تم تطبيقه

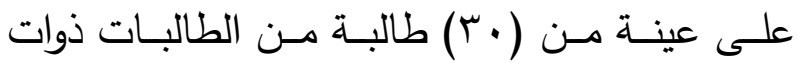

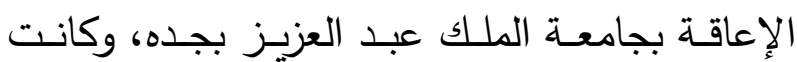

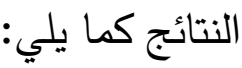

جدول (1) معاملات ارتباط عبارات مقياس الرفاهية النفية مع البعد الذي تنتمي إليه

\begin{tabular}{|c|c|c|c|c|c|c|c|c|c|c|c|}
\hline \multicolumn{2}{|c|}{ تقبل الذات } & \multicolumn{2}{|c|}{ الهاف من الحياة } & \multicolumn{2}{|c|}{ العلاقات الإيجابية } & \multicolumn{2}{|c|}{ النمو الثخصي } & \multicolumn{2}{|c|}{ التمكن البيئي } & \multicolumn{2}{|c|}{ الاستقلالية } \\
\hline معامل الارتباط & $\varepsilon$ & معامل الارتباط & $\varepsilon$ & معامل الارتباط & $\varepsilon$ & معامل الارتباط & $\varepsilon$ & معامل & $\varepsilon$ & الارتباط & $\varepsilon$ \\
\hline $.803 * *$ & 6 & $.485^{* * *}$ & 5 & $.486 * *$ & 4 & $.527 * *$ & 3 & $.575^{* *}$ & 2 & $.378 *$ & 1 \\
\hline $.760 \% *$ & 12 & .034 & 11 & $.436 * *$ & 10 & $.591 * *$ & 9 & .080 & 8 & $.301 *$ & 7 \\
\hline .256 & 18 & $.579 * *$ & 17 & $.347 *$ & 16 & $.454 * *$ & 15 & $.528 * *$ & 14 & $.357 *$ & 13 \\
\hline $.715^{* * *}$ & 24 & $.615^{* * *}$ & 23 & $.457 * *$ & 22 & $.671 * *$ & 21 & $.505 * *$ & 20 & .089 & 19 \\
\hline $.337 \%$ & 30 & $.418^{* * *}$ & 29 & $.593 * *$ & 28 & $.412 * *$ & 27 & $.496 * *$ & 26 & $.377 *$ & 25 \\
\hline $.491 \% *$ & 36 & $.335 *$ & 35 & $.449 * *$ & 34 & $.680 * *$ & 33 & $.374 \%$ & 32 & .109 & 31 \\
\hline $.785^{* * *}$ & 42 & $.586 * *$ & 41 & .024 & 40 & .260 & 39 & $.601^{* *}$ & 38 & .039 & 37 \\
\hline
\end{tabular}

يدل على انتماء العبارات إلى أبعادها، وتؤكد هذه النتائج صدق المقياس المستخدم في الدراسة الحالية. الصدق البنائي: - 2 - إن

وتم التحقق منهـ بحساب معامل ارتباط بيرسون بين درجة كل بعد من أبعاد الرفاهية النفسية (الاستقلالية - الـتمكن البيئي - النمـو الشخصـي - العلاقـات الايجابيــة - الهـدف مـن الحيــاة - تقبـلـل الحيــاة) والدرجة الكلية للمقياس، والجدول التالي يوضـح هذه

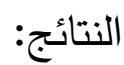

يتضح من جدول (1) أن معاملات ارتباط عبارات المقياس مع البعد الذي تتتمي إليه تراوحت ما بين

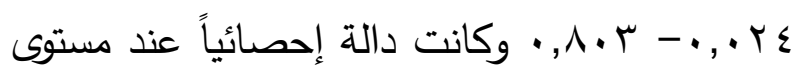
ب.,.

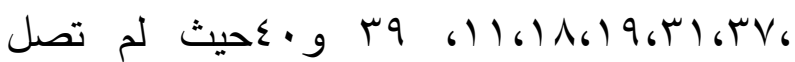
معاملات الارتباط الخاصة بها إلى مستوى الدلالة ولذا سيتم حذفها من المقياس عند اجراء التحليلات الاحصائية الخاصة بالتحقق من الفروض. أما باقي معاملات الارتباط فكانت بين المقبولة والمرتفعة. مما 
جدول (Y) معاملات ارتباط بيرسون بين أبعاد مقياس الرفاهية النفسية والدرجة الكلية للمقياس

\begin{tabular}{|c|c|}
\hline الارجة الكلية على مقياس الرفاهية النفسية & 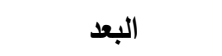 \\
\hline $.699^{\circ *}$ & الاستقلالية \\
\hline $.486^{* *}$ & التمكين البيئي \\
\hline $.610^{* *}$ & 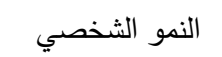 \\
\hline $.354^{\prime \prime}$ & العلاقات الإيجابية \\
\hline $.494^{* *}$ & الهدف من الحياة \\
\hline $.583^{* *}$ & تقبل الذات \\
\hline
\end{tabular}

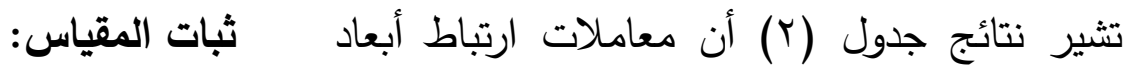

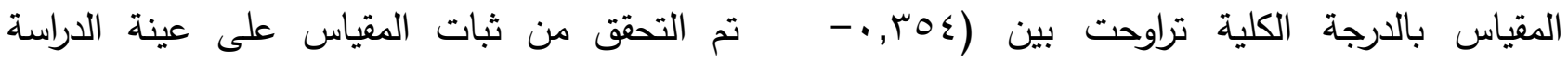
999

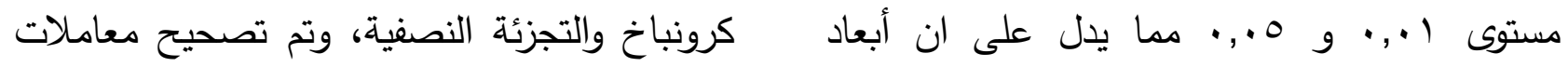
المقياس تقيس المراد منها قياسه، مما يؤكد صدق الارتباط الناتجة باستخدام معادلة سبيرمان - براون ومعادلة جتمان، والجدول رقم (ب) يوضح هذأنه الاتساق الداخلي للمقياس. النتائج:

جدول (r) معاملات ثبات الفا كرونباخ لمقياس الرفاهية النفسية وأبعاده

\begin{tabular}{|c|c|c|c|c|}
\hline معامل جتمان & معامل سبيرمان-براون & التجزئة النصفية & ثبات الفا كرونباخ & \\
\hline .602 & .632 & .603 & .672 & الاستقلالية \\
\hline .702 & .707 & .660 & .677 & التمكين البيئي \\
\hline .786 & .799 & .701 & .727 & النمو الثخصي \\
\hline .730 & .733 & .670 & .790 & العلاقات الإيجابية \\
\hline .650 & .651 & .626 & .791 & الهذف من الحياة \\
\hline .682 & .685 & 617 & .694 & تقبل الذات \\
\hline .776 & .795 & .660 & .755 & الدرجة الكلية \\
\hline
\end{tabular}

من الجدول السابق يتضح أن قيم معامل ثبات المقياس بدرجة مقبولة من الثبات تجعل الباحثة مقياس الرفاهية النفسية للأبعاد والدرجة الكلية تطمئن إلى استخدامه في الدراسة الحالية.

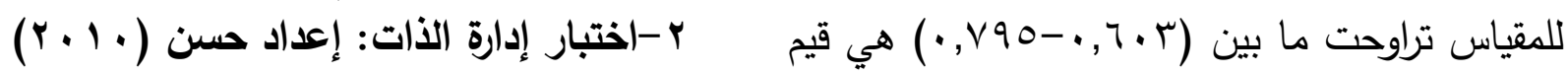

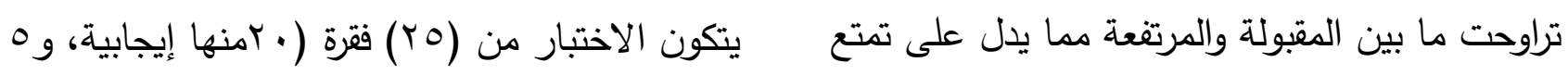
سلبية) تشمل أبعاد إدارة الذات الأربعة وهي (أهداف الاحن 
فقرة متضمنة فيه والدرجة الكلية له، وتراوحت معامل

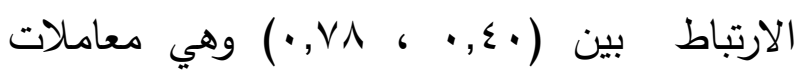

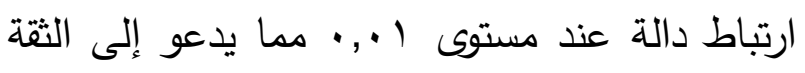
في النتائج التي يمكن التوصل إليها عند استخدام

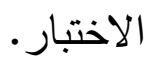

ثبات الاختبار: استخدم معد الاختبار طريقة تحليل التباين لإيجاد معامل ثبات الاختبار ، حيث بلغ ثباته

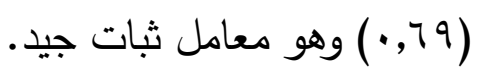
التحقق من الثروط السيكومترية لاختبار إدارة الأات في الدراسة الحالية:

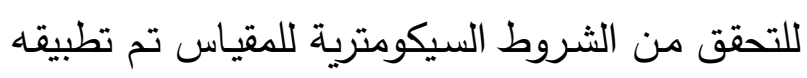
على عينة الدراسة الاستطلاعية السابق الاشارة إليها

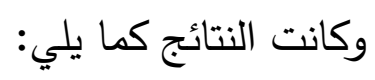

• الصدق: تم حساب الصدق وذلك من خلال:

صدق الاتساق الداخلي: وتم بحساب معامل ارتباط بيرسون بين كل من: درجة كل فقرة مع الدرجة الكلية

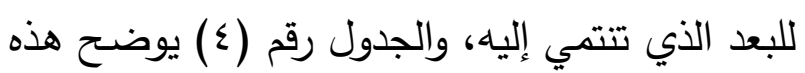

النتائج:
الذات-التخطيط للذات- العلاقات مع الآخر - رقابة وتقويم الذات) وأمام كل فقرة خمسة بدائل للإجابة (أوافق بشدة، أوافق، محايد، أعارض، أعارض بش بشدة

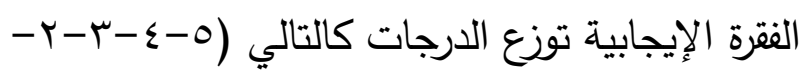

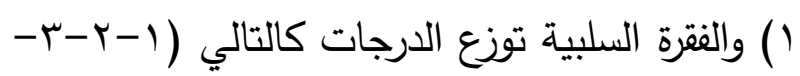
. (0-乏

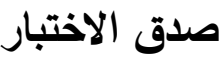
الصدق العاملي: قام معد الاختبار بحساب معاملات الصدق العاملية وذلك عن طريق حساب متوسط معل الصاب التشبعات الدالة لكل بعد وتم اتخاذ هذا المتوسط مؤشراً لمعاملات صدق الاختبار : بلغت متوسطات الصدق العاملية لكل بعد كالتالي (أهداف الذات

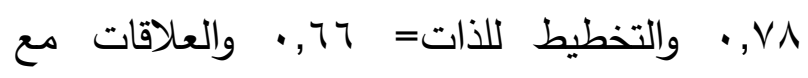

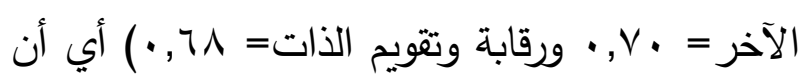

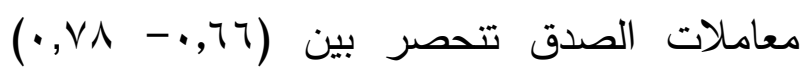
وهي معاملات صدق جيدة. صدق المفردات: اعتمد معد الاختبار لحساب صدقد صدق صدات

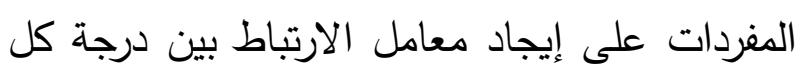
جدول (؛) معاملات ارتباط عبارات مقياس ادارة الذات مع البعد الذي تنتمي إليه

\begin{tabular}{|c|c|c|c|c|c|c|c|c|c|}
\hline \multicolumn{2}{|c|}{ رقابة وتقويم الذات } & \multicolumn{4}{|c|}{ العلاقات مع الآخر } & \multicolumn{2}{|c|}{ التخطيط للذات } & \multicolumn{2}{|c|}{ اهداف الذات } \\
\hline معامل الارتباط & $\varepsilon$ & معامل الارتباط & $\varepsilon$ & معامل الارتباط & $\varepsilon$ & معامل الارتباط & $\varepsilon$ & معامل الارتباط & $\varepsilon$ \\
\hline $.740^{* *}$ & 10 & $.461^{\prime \prime}$ & 21 & $.569^{* * *}$ & 1 & $.651^{* *}$ & 3 & $.642^{* *}$ & 5 \\
\hline $.543^{* *}$ & 11 & $.472^{* *}$ & 22 & $.591^{* * *}$ & 2 & $.530^{* *}$ & 6 & $.773^{* * *}$ & 7 \\
\hline $.621^{* *}$ & 13 & $.613^{* *}$ & 23 & .236 & 4 & $.400^{*}$ & 9 & $.682^{* * *}$ & 24 \\
\hline $.375^{*}$ & 15 & - & - & $.516^{* *}$ & 8 & $.425^{*}$ & 14 & $.740^{* *}$ & 25 \\
\hline- & - & - & - & .149 & 12 & $.415^{*}$ & 17 & - & - \\
\hline- & - & - & - & $.425^{*}$ & 16 & .259 & 19 & - & - \\
\hline- & - & - & - & $.472^{* * *}$ & 18 & $.385^{\prime \prime}$ & 20 & - & - \\
\hline
\end{tabular}




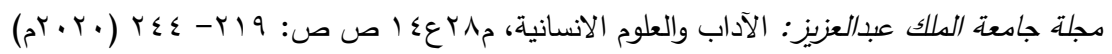 DOI:10.4197/Art.28-14.6}

أبعادها، وتؤكد هذه النتائج صدق المقياس المستخدم في الدراسة الحالية.

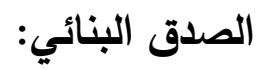

وتم التحقق منسه بحساب معامل ارتباط بيرسون بين درجة كل بعد من ابعاد ادارة الذات (اهداف الذات -

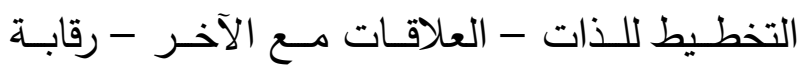
وتقـويم الـذات) والدرجـة الكليـة للمقيـاس، والجدول

التالي يوضح هذه النتائج: وكانت نتيجة معاملات الارتباط كالتالي:

يتضح من جدول (乏) أن معاملات ارتباط عبارات المقياس مع البعد الذي تنتمي إليه تراوحت ما بين

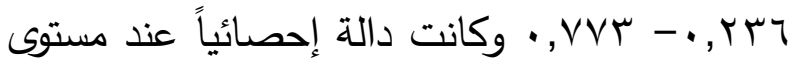

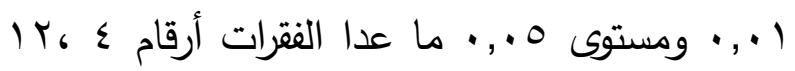
و9 احيث لم تصل معاملات الارتباط الخاصة بها إلي مستوى الدلالة ولذا سيتم حذفها من المقياس عند اجراء التحليلات الاحصائية الخاصة بالتحقق من الفروض. أما باقي معاملات الارتباط فكانت بين المقبولة والمرتقعة. مما يدل على انتماء العبارات إلى دلى

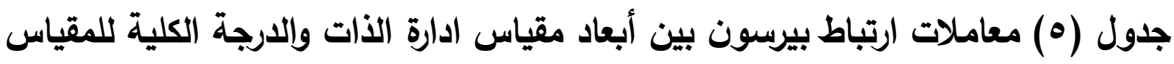

\begin{tabular}{|c|c|}
\hline الدرجة الكلية علي مقياس ادارة الذات & 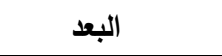 \\
\hline $.763^{* *}$ & اهداف الذات \\
\hline $.728^{* *}$ & التخطيط للذات \\
\hline $.735^{* *}$ & العلاقات مع الآخر \\
\hline $.634^{* *}$ & رقابة وتقويم الذات \\
\hline
\end{tabular}

تشير نتائج جدول (0) أن معاملات ارتباط أبعاد ثبات المقياس: تم التحقق من ثبات المقياس على المقياس بالدرجة الكلية تراوحت بين (عبا7,-- عينة الدراسة الاستطلاعية السابق الإشارة إليها

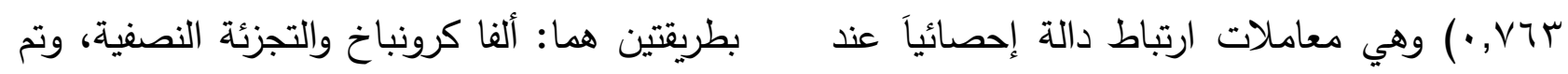
مستوى ا •, • مما يدل على ان أبعاد المقياس تقيس تصحيح معاملات الارتباط الناتجة باستخدام معادلة المراد منها قياسـ، مما يؤكد صدق الاتساق الداخلي سبيرمان - براون ومعادلة جتمان، والجدول رقم (7) يوضتح هذه النتائج: للمقياس. جدول (†) معاملات ثبات الفا كرونباخ لمقياس ادارة الذات وأبعاده

\begin{tabular}{|c|c|c|c|c|}
\hline معامل جتمان & معامل سبيرمان-براون & التجزئة النصفية & ثبات الفا كرونباخ & \\
\hline .702 & .718 & .662 & .713 & اهداف الذات \\
\hline .657 & .662 & .590 & .629 & التخطيط للذات \\
\hline .642 & .643 & .579 & .703 & العلاقات مع الآخر \\
\hline .641 & .656 & .585 & .671 & رقابة وتقوبم الذات \\
\hline .701 & .705 & .610 & .772 & الارجة الكلية \\
\hline
\end{tabular}

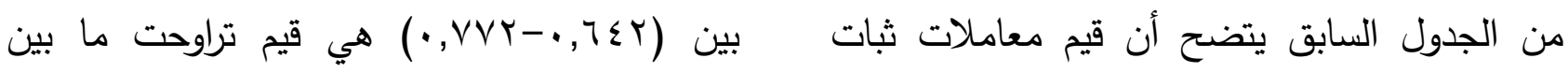
المقياس للأبعاد والدرجة الكلية للمقياس تراوحت ما المقبولة والمرتفعة مما يدل على تمتع المقياس بدرجة 


$$
\text { أحلام علي أحمد الزهراني و مجدة السيد علي الكثكي }
$$

rr.

- المتوسط الحسابي والانحراف المعياري. - الاختبار التائي لعينة واحدة.

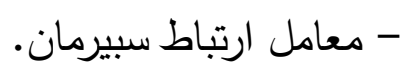
- اختبار مان ويتتي.

نتائج الدراسة ومناقشتها:

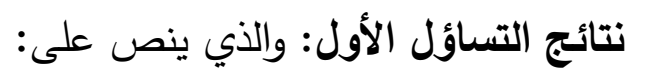
" ما مستوى الرفاهية النفسية لدى عينة من الطالبات

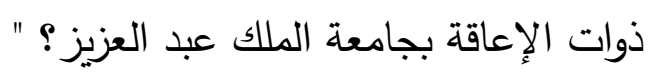
استخدم اختبار ت لعينة واحدة وذلك لمقارنة متوسط لإعل

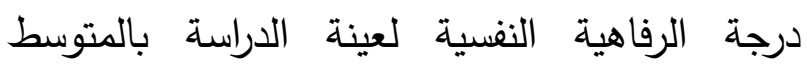
الفرضي للمقياس ويوضح ذلك الجدول التالي:

مقبولة من الثبات تجعل الباحثة تطمئن إلى استخدامه في الدراسة الحالية.

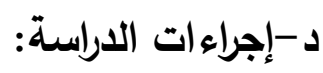
- الاطلاع على الإطار النظري والدراسات السابقة

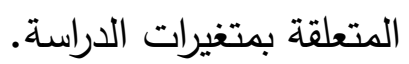
- تحديد العينة وتحديد المقاييس التي سيتم لتعرلت استخدامها. - - تطبيق أدوات الدراسة على العينة، وتصحيح المقاييس واستخراج الدرجات والتحقق من الفروض.

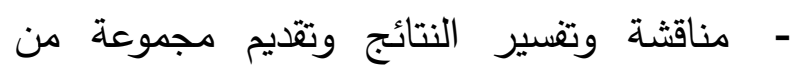
التوصيات والبحوث المقترحة. الأساليب الإحصائية المستخدمة: للإجابة على ولى أسئلة الدراسة وللتحقق من فروضها تم إجراء التحليلات الإحصائية الآتية:

جدول (v)

نتائج الفروق بين المتوسط الحسابي والمتوسط الفرضي لعينة الاراسة على مقياس الرفاهية النفسية

\begin{tabular}{|c|c|c|c|c|c|c|}
\hline مستوى اللالاة & قيمة ت & درجة الحرية & المعياري & الفرضي & الحسابي & عدد العينة \\
\hline 0.001 & 7.496 & 46 & 24.23 & 147 & 173.49 & 47 \\
\hline
\end{tabular}

* يقصد بالمتوسط الفرضي هو جمع أوزان بدائل الاستجابة وقسمتها على عددها ثم ضرب الناتج في عدد فقرات المقياس.

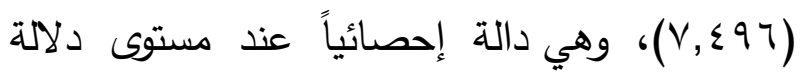

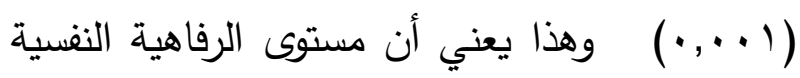

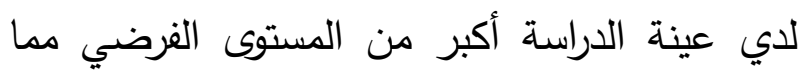

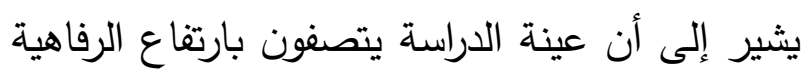

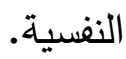

تم حساب متوسط درجات العينة الكلية على مقياس

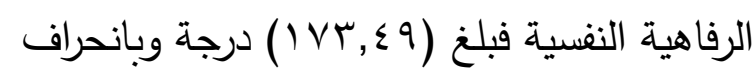

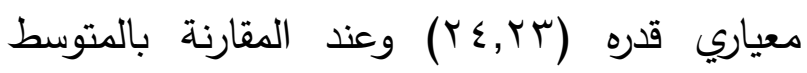

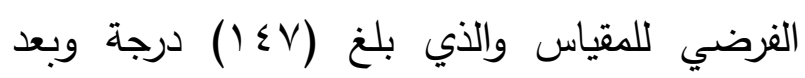
تطبيق الاختبار التائي لعينة واحدة تبين أن القيمة

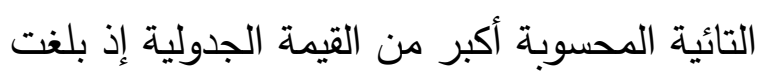


وتتقق هذه النتيجة مع نتائج الدراسات السابقة مثل الرفاهية النفية تشير إلى التحديات الوجودية التي

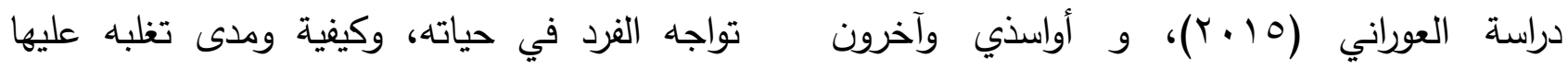

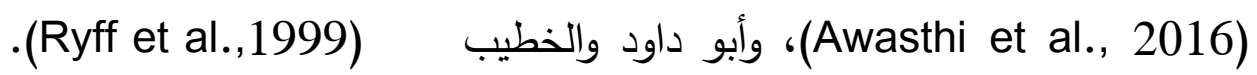

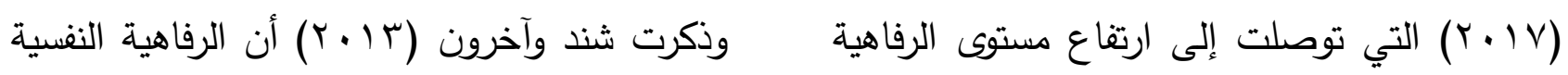

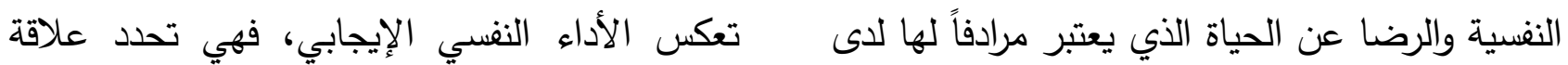

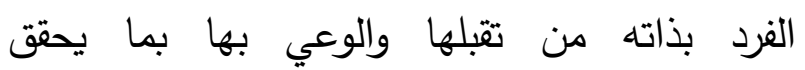

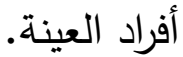

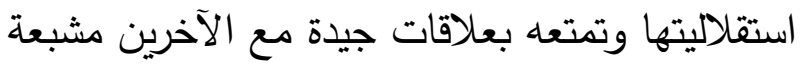

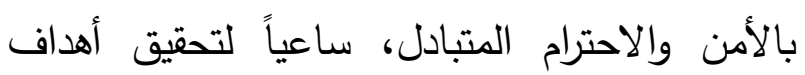
ومقاصد حياتية يتبناها من خلال استغلاله لكافة الفرص البيئية وتغلبه على ما يواجهه من معوقات،

بما يحقق له التقدم والاستمرارية والنمو الثخصي. التساؤل الثاني: والذي ينص على:

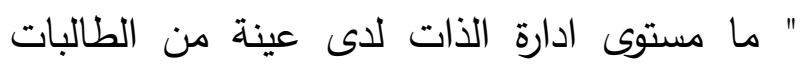
ذوات الإعاقة بجامعة الملك عبد العزيز؟ " . وللكشف عن مستوى إدارة الذات لاى عينة الدراسة

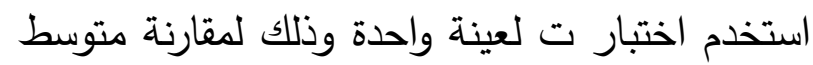
درجة إدارة الذات لعينة الدراسة بالمتوسط الفرضي للمقياس ويوضح ذلك الجدول التالي:

وترجع الباحثتان هذه النتيجة إلى الاهتمام الملحوظ من قبل حكومتنا الرشيدة في تلبية احتياجات هذه الفئة، وكذلك أصبحت المعينات والوسائل متطورة، ساهم ذلك في تحسين نوعية حياتهن ومواجهة الصعوبات والتحديات التي يتعرضن لها، وتطوير

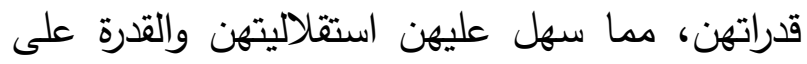
بناء علاقات جيدة دع الآخرين، واحساسهن بأن اسنعان حياتهن ذات معنى، لعل ذلك جعل مستوى الرفاهية

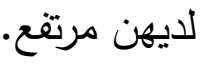
ويتقق ذلك مع ما قدمته رايف وزملاؤها في الإطار

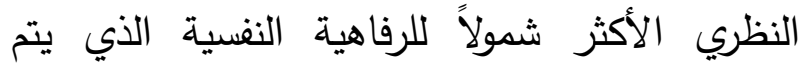

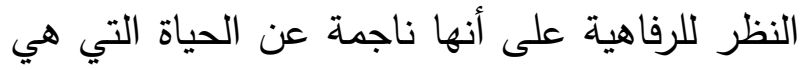

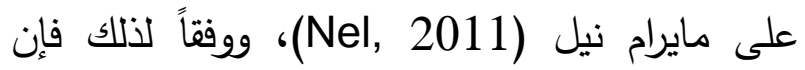
جدول (^)

نتائج الفروق بين المتوسط الحسابي والمتوسط الفرضي لعينة الدراسة على مقياس ادارة الذات

\begin{tabular}{|c|c|c|c|c|c|c|}
\hline مستوى اللالالة & قيمة ت & درجة الحرية & المعياري & الفرضي & الحسابي & عدد العينة \\
\hline 0.001 & 15.12 & 46 & 7.85 & 75 & 92.32 & 47 \\
\hline
\end{tabular}

" يقصد بالمتوسط الغرضي هو جمع أوزان بدائل الاستجابة وقستها على عددها ثم ضرب الناتج في عدد فقرات المقياس. 
وترى الباحثتان أن ذوات الإعاقة لديهن من الحقوق

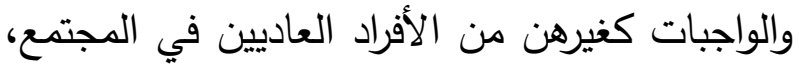

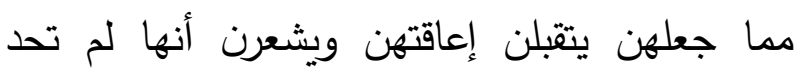

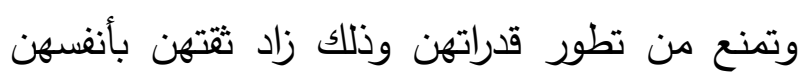
وقوة إرادتهن، مما أسهر ذلك في القدرة على مواجهة الصعوبات والمواقف التي يتعرضن لها من خلال اكتساب أساليب ومهارات تمكنهن من إدارة وتنظيم ذواتهن بشكل ناجح. ويؤكد ذلك ما ذكره أبو هدروس (10 ب ب) بأن قدرة الفرد الذاتية على إدارة أمور حياته المختلفة بفاعلية ونجاح، وذلك من خلال امتلاكه مجموعة من المن الماته

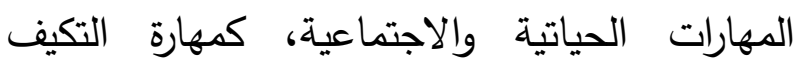
والتوافق مع الظروف الطارئة، ومهارة التعامل مع

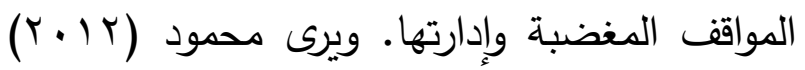
أن إدارة الذات مجموعة من المهارات والآليات يستخدمها الفرد في مواقف متعددة لتحسين سلوكه

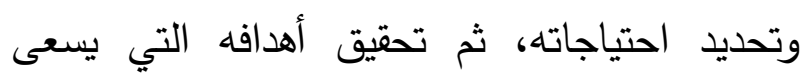
إليها. نتائج الفرض الأول: والذي ينص على:

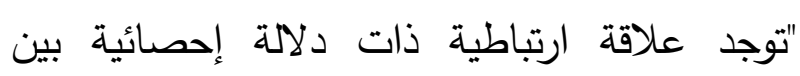
الرفاهية النفسية وإدارة الذات لدى عينة من الطالبات ذوات الإعاقة بجامعة الملك عبد العزيز" للتحقق من صحة هذا الفرض استخدم معامل ارتباط بيرسون لحساب العلاقة بين المتغيرات والجدول

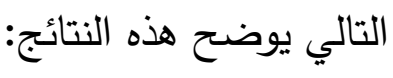

تم حساب متوسط درجات العينة الكلية على مقياس إدارة الذات فبلغ (r, بوج) درجة وبانحراف معياري قدره للمقياس والذي بلغ (V0) درجة وبعد تطبيق الاختبار التائي لعينة واحدة تبين أن القيمة التائية المحسوبة

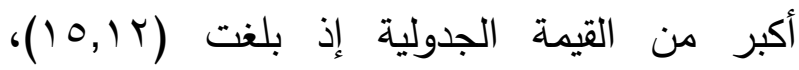

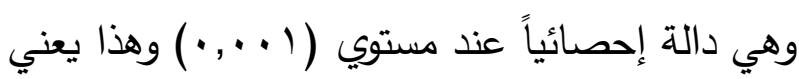
أن مستوى ادارة الذات لدي عينة الدراسة أكبر من إنداتيات المستوى الفرضي مما يشير إلى أن عينة الدراسة النه يتصفون بارتفاع ادارة الذات. وتتفق مع هذه النتيجة مع دراسة أبو العمرين

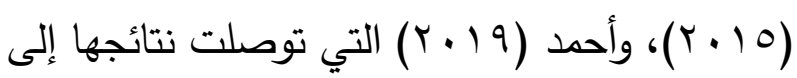
أن مستوى إدارة الذات وأحد أبعاده لاى أفراد العينة من الصم ومن ذوي الإعاقة مرتفع. ويمكن تفسير هذه النتيجة في ضوء الإعنه هرئع دأدب النظري في تفسير سلوك إدارة وتنظيم الذات، فنجاح الفرد في

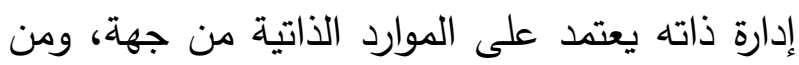

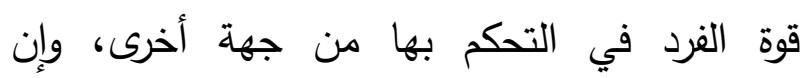
الجوانب الإرادية لإدارة الذات تتمثل في الميكانيزمات التي تقام من أجل ضبط التركيز لتحقيق النجاح، وذلك في مواجهة المعوقات الذاتية والبيئية التي لتي لتئي يتعرض لها الفرد، وبالتالي فإن إدارة الذات تعتمد على توفر إرادة قوية (Denise\& John, 2006) نقلاً عن (ياسين وآخرون، 0 ( • ب). 


$$
\text { أحلام علي أحمد الزهراني و مجدة السيد علي الكثكي }
$$

rr.

\section{جدول (9) جان (9)}

معاملات ارتباط بيرسون بين الرفاهية النفسية وادارة الذات لاى عينة الاراسة (ن = \؛)

\begin{tabular}{|c|c|c|c|c|c|}
\hline \multicolumn{5}{|c|}{ ادارة الذات } & \multirow[t]{2}{*}{ الرفاهية النفسية } \\
\hline الارجة الكلية & رقابة وتقويم الذات & العلاقات مع الآخر & التخطيط للذات & اهداف الذات & \\
\hline .129 & .064 & .131 & $-.062-$ & .181 & الاستقلالية \\
\hline $.307^{*}$ & .188 & .053 & $.418^{* * *}$ & $.307^{\circ}$ & التمكين البيئي \\
\hline $.515^{* *}$ & $.437^{* * *}$ & $.342^{*}$ & $.318^{\circ}$ & $.349^{*}$ & النمو الثخصي \\
\hline .276 & .190 & $.476^{* *}$ & .015 & .056 & العلاقات الإيجابية \\
\hline .034 & .162 & .100 & .159 & .013 & الههف من الحياة \\
\hline $.503^{* *}$ & $.316^{*}$ & $.398^{* *}$ & .276 & $.387^{* *}$ & تقبل الذات \\
\hline $.443^{* *}$ & .259 & $.376^{* *}$ & .212 & $.347^{*}$ & الارجة الكلية \\
\hline
\end{tabular}

معاملات دالة عند مستوي معنوية 0 ., .

الكلية ما عدا الارتباط بين تقبل الذات وبعد التخطيط داته

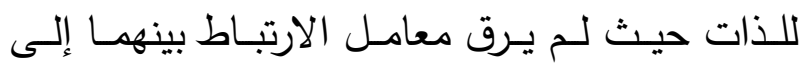

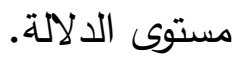
أما الدرجة الكلية للرفاهيـة النفسية فقد ارتبط ارتباط

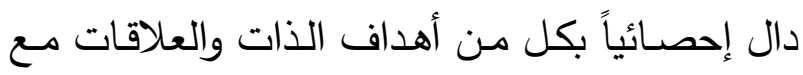
الآخر والدرجة الكلية لإدارة الذات، ولم ترق العلاقة بينها وبين بعدي التخطيط للذات ورقابة وتقويم الذات

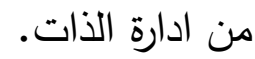
أمسا بعدي الاستقلالية والهدف من الحياة من أبعاد

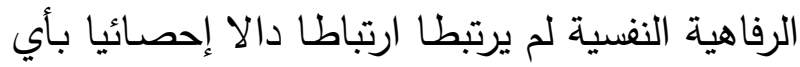

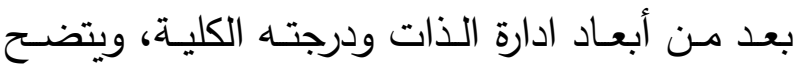
أيضـا ان بعد التمكين البيئي لـم يـرتبط بشكل دال دال

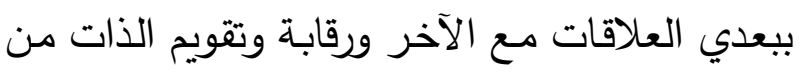

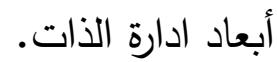
وقد اتخذت هذه العلاقات سواء الدالة إحصـائيا أو

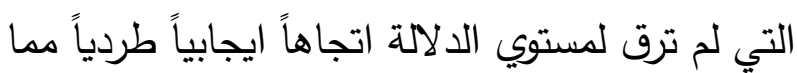

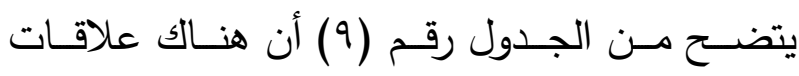

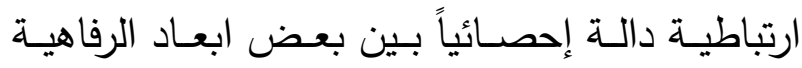

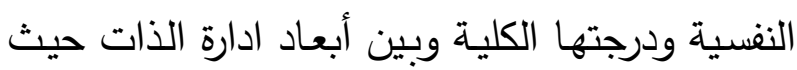
ارتبط بعد التمكين البيئي من أبعاد الرفاهية النفسية

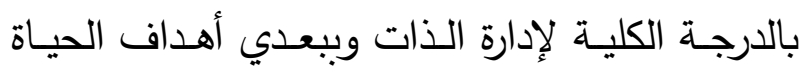
والتخطيط للـذات، أمـا العلاقـة بـين التمكين البيئي وبعدي العلاقات مـع الآخر ورقابة وتقويم الذات فلم ترق لمستوي الدلالة الإحصائية.

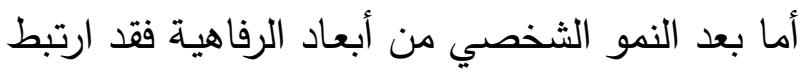
بشكل دال إحصائياً بالدرجة الكلية على مقياس ادارة الذات وجميع أبعاده، وارتبط بعد العلاقات الايجابية

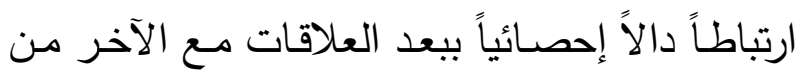
ادارة الذات ولم ترق باقي معاملات ارتباطـه بـإدارة الذات إلى مستوى الدلالة الاحصائية.

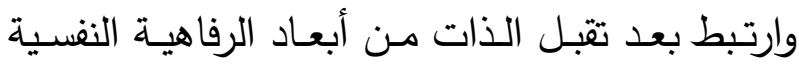

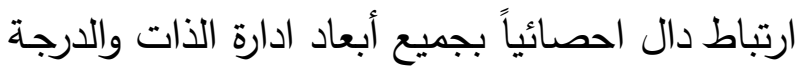


قادرات على الوصول إلى معرفة نقاط القوة والضعف لـديهن ويسـتطعن التعـرف على طاقـاتهن لتحقيـق أهدافهن، ومراقبة ومتابعة نتائج التخطيط لتحقيق تلك الأهداف باسـتمرار ، كلمـا جعلهن قـادرات على إدارة ذواتهن بنجاح وبالتالي يصبح لديهن شعور بالرفاهية النفسية والعكس صحيح.

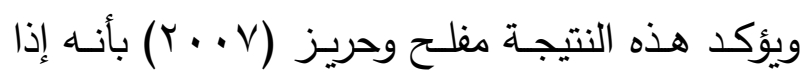
تحسنت إدارة الفرد لذاته فإنه سيسعد في حياته، كما Johansson et al., ) يذكر جوهانسون وآخرون 2007) أن زيـادة قدرة الفـرد على إدارة ذاته يـؤدي إلى إحساسـ بالسعادة والعكس صحيح. نتائج الفرض الثاني : والذي ينص على: "توجد فروق ذات دلالة إحصائية بين متوسطي درجات الرفاهية النفسية لدى عينة الدراسة تعزى لنوع الإعاقة (الجسدية- الحسية)" للتحقق من صحة هذا الفرض تم استخدام اختبار مان ويتني لعينتين مستقلتين والجدول التالي يوضح

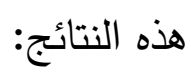

يعنـي إنـا كلهـا زادت درجـة الرفاهيـة النفسـية زادت درجة ادارة الذات والعكس صحيح. وبهذا نقبل جزئيا فرض الدراسـة الأول القائل بوجود علاقـة ارتباطيـة ذات دلالــة إحصـائية بـين الرفاهيـة

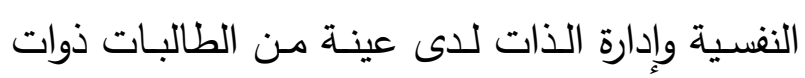
الإعاقة بجامعة الملك عبد العزيز. وتتفـق هذه النتيجـة مـع دراسـات كل مـن القطـاوي

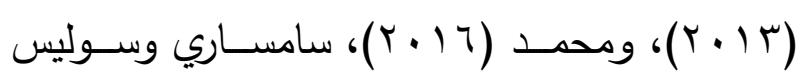
(Samsari \& Soulis, 2019) النتائج وجود علاقة ارتباطية بين الرفاهية النفسية أو أو أحد أبعادها وإدارة الذات أو أحد أبعادها.

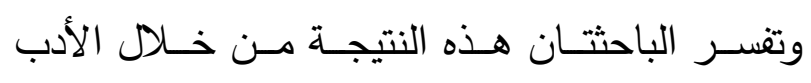
النظري الذ يرى أنسه إذا كان للفرد هدف محدد يعمل على تحقيقـه بشـكل جيـد، فـإن النجـاح في تحقيقـه يوصله إلى السعادة، والفشل في تحقيقه سيؤدي إلى التعاسة (Diener, 1984). وكمـا ترى الباحثـة أن وجـود إدارة الذات لدى الفـرد يحسـن مـن شـعوره بالرفاهيـة النفسية، ولدى الأفراد

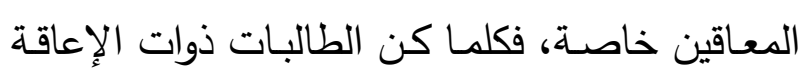




\section{جدول رقم (· (1)}

نتائج اختبار مان ويتني لدلالة الفروق بين متوسطي رتب درجات عينة الدراسة على مقياس الرفاهية النفسية وفقا لنوع الإعاقة (الجسدية- الحسية)

\begin{tabular}{|c|c|c|c|c|c|c|}
\hline \multirow{2}{*}{ مستوى الدلالة } & \multirow{2}{*}{ قيمة ز } & \multicolumn{2}{|c|}{ الجسدية (ن = ؟ ؟ ) } & \multicolumn{2}{|c|}{ الحسية (ن= rrr) } & \multirow{2}{*}{ البعد نوع الاعاقة } \\
\hline & & مجموع الرتب & متوسط الرتب & مجموع الرتب & متوسط الرتب & \\
\hline غير دالة & 1.847 & 715.50 & 21.68 & 412.50 & 29.46 & الاستقلالية \\
\hline غير دالة & -.561 & 816.00 & 24.73 & 312.00 & 22.29 & التمكين البيئي \\
\hline غير دالة & -.584 & 767.00 & 23.24 & 361.00 & 25.79 & النمو الثخصي \\
\hline غير دالة & -.105 & 787.50 & 23.86 & 340.50 & 24.32 & العلاقات الإيجابية \\
\hline غير دالة & -.630 & 765.00 & 23.18 & 363.00 & 25.93 & الهدف من الحياة \\
\hline غير دالة & -.629 & 765.00 & 23.18 & 363.00 & 25.93 & تقبل الذات \\
\hline غير دالة & -1.268 & 737.50 & 22.35 & 390.50 & 27.89 & الارجة الكلية \\
\hline
\end{tabular}

فروق في مستوى الرفاهية النفسية والرضا عن الحياة بين أنواع الإعاقات وهذا ما يؤكد نتيجة الفرض. وترجع الباحثتان هذه النتيجة إلى الظروف المتثابهة التي تعيشها ذوات الإعاقة بجميع أنواعها، ونوعية الخدمات التي المقدمة لهن على حداً سواء، وطرق تفاعلهن مع البيئة والتعايش معها، بغض النظر عن نوع إعاقتهن، لعل ذلك سبب تساوي الطالبات ذوات الإعاقة الجسدية وذوات الإعاقة الحسية في الرفاهية النفسية.

نتائج الفرض الثالث : والذي ينص على : "توجد فروق ذات دلالة إحصائية بين متوسطي درجات ادارة الذات لدى عينة الدراسة تعزى لنوع الإعاقة (الجسدية- الحسية)" للتحقق من صحة هذا الفرض تم استخدام اختبار مان ويتي لعينتين مستقلتين والجدول التالي يوضح : - ذه النتائج
من الجدول السابق يتضح أنه لا توجد فروق دالة إحصائيا لدي عينة الدراسة تعزي لمتغير نوع الاعاقة في الرفاهية النفسية بجميع أبعادها، حيث تراوحت

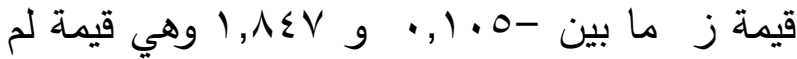

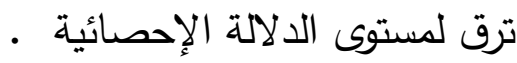
وبذلك نرفض الفرض الثاني من فروض الدراسة والذي ينص وجود فروق ذات دلالة إحصائية بين متوسطي درجات الرفاهية النفسية لدى عينة الدراسة تعزى لنوع الإعاقة (الجسدية- الحسية). وتتفق هذه النتيجة مع نتائج دراسات العوراني

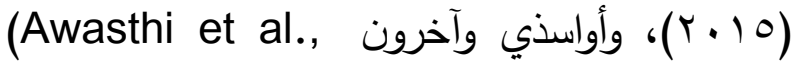

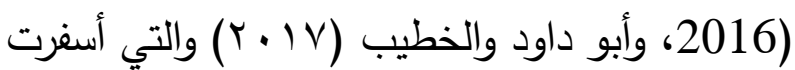
نتائجها إلى أن مستوى الرفاهية النفسية و الرضا عن الحياة وهو أحد مرادفات الرفاهية النفسية لدى ذوي الإعاقة (السمعية- البصرية- الحركية) كان بنفس المستوى، حيث اتضح في هذه الدراسة أنه لا يوجد 


$$
\text { أحلام علي أحمد الزهراني و مجدة السيد علي الكثكي }
$$

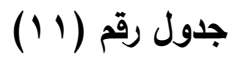

نتائج اختبار مان ويتني لالالة الفروق بين متوسطي رتب درجات عينة الدراسة على مقياس ادارة الذات وفقا لنوع الإعاقة

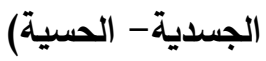

\begin{tabular}{|c|c|c|c|c|c|c|}
\hline \multirow{2}{*}{ مستوى الدلالة } & \multirow{2}{*}{ قيمة ز } & \multicolumn{2}{|c|}{ الجسدية (ن = \& \&) } & \multicolumn{2}{|c|}{ الحسية (ن=rr) } & \multirow{2}{*}{ البعد } \\
\hline & & مجموع الرتب & متوسط الرتب & مجموع الرتب & متوسط الرتب & \\
\hline غير دالة & -.883 & 754.50 & 22.86 & 373.50 & 26.68 & اهداف الذات \\
\hline غير دالة & -.622 & 818.50 & 24.80 & 309.50 & 22.11 & التخطيط للذات \\
\hline غير دالة & -.317 & 778.50 & 23.59 & 349.50 & 24.96 & العلاقات مع الآخر \\
\hline غير دالة & -.247 & 781.50 & 23.68 & 346.50 & 24.75 & رقابة وتقويم الذات \\
\hline غير دالة & -.547 & 768.50 & 23.29 & 359.50 & 25.68 & الدرجة الكلية \\
\hline
\end{tabular}

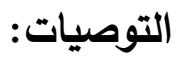

في ضوء النتائج التي توصلت إليها الدراسة يمكن

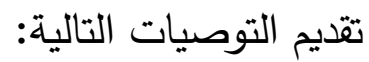

1- تقديم دورات تدريبية لطالبات ذوات الإعاقة من لن

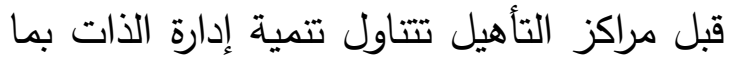
ينعكس على الرفاهية النفسية لديهم. r- عقد ورش عمل من قبل مركز ذوي الاحتياجات الخاصة لتدريب الطالبات ذوات الإعاقة على مركى دوي الاحتيات الاستقلالية وتقبل الذات وكيفية رقابة وتقييم ذواتهن. r- إعداد وتقديم برامج من قبل وزارة الإعلام تعمل على إرشاد وتوعية أسر الطالبات ذوات الإعاقة والمجتمع بتتاول أهمية الرفاهية النفسية وإدارة الذات وأثرها على هذه الفئة.

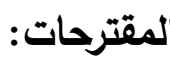
وفي ضوء ما توصلت إليه الدراسة الحالية من نتائج يمكن إجراء مجموعة من الدراسات

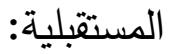

من الجدول السابق يتضح أنه لا توجد فروق دالة إحصائيا لدي عينة الدراسة تعزي لمتغير نوع الاعاقة

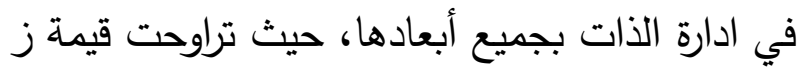

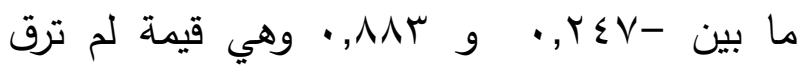
لمستوي الدلالة الإحصائية. وبذلك نرفض الفرض الثالث من فروض الدراسة والذي ينص علي وجود فروق ذات دلالة إحصائية بين متوسطي درجات إدارة الذات للى عينة الدراسة تعزى لنوع الإعاقة (الجسدية- الحسية).

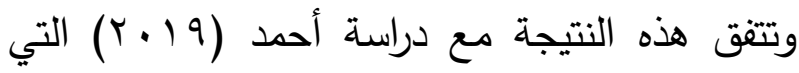

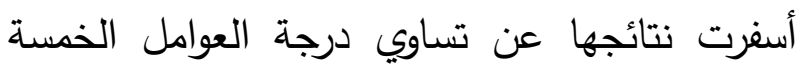

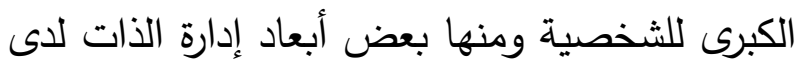
الطلاب المعاقين بجامعة الفاشر باختلاف إعاقاتهم. ترجع الباحثتان هذي النتيجة إلى الدورات وورش العمل التي يقدمها مركز ذوي الاحتياجات الخاصة بالجامعة للطالبات ذوات الإعاقة التي قاربت بين دالين جميع ذوات الإعاقة في إدارة الذات مما جعلهن على لئ رؤية واحدة واضحة رغم اختلاف إعاقتهن. 
رجب، عبد الفتاح؛ مطر، علي محمد.

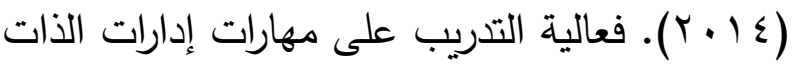
في الحد من السلوك الصفي المشكل وأثره في تحسين مفهوم الذات الأكاديمي لدى تلاميذ المرحلة الإعدادية. مجلة التربية الخاصة، كلية التربية

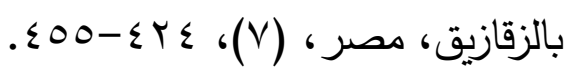

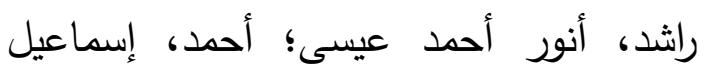
عثمان حسن. (10 (1). رعاية ذوي الاحتياجات الخاصة من المنظور الإسلامي. مجلة كلية التنمية البشرية، (1)، 0 (1)-11)

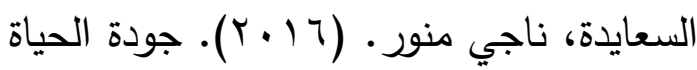
لاى المعاقين سمعياً في ضوء بعض ناهن المتغيرات

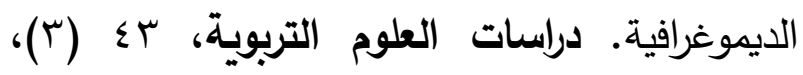
.r. $\{r-r \cdot r)$

شعبان، حمدي سعد محمد. (r ا • r). التتظيم الذاتي وعلاقته بتقدير الذات لاى عينة من ذوي الإعاقة البصرية. مجلة كلية التربية، كلية التربية، وعاته

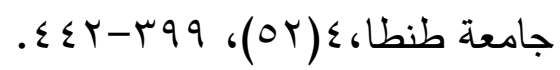

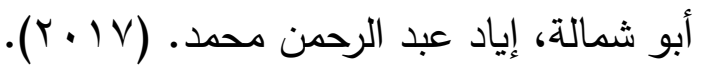

إدارة الذات كمتغير وسيط بين الحساسية الانفعالية والتوجه نحو الحياة للطلبة ذوي الإعاقة السمعية ببرنامج التعليم الجامعي بالجامعة الإسلامية بغزة. رسالة ماجستير، قسم علم النفس، كلية التربية

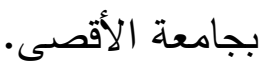

شند، سميرة محمد؛ هيبة، حسام إسماعيل؛

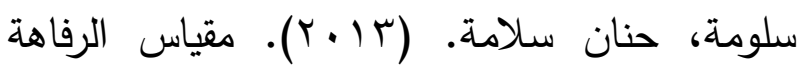

1- الرفاهية النفسية وعلاقتها بإدارة الذات لدى جميع فئات المجتمع. r- التنظيم العاطفي وعلاقته بالرفاهية النفسية لدى الأطفال من ذوي الإعاقة. r- الأنشطة الترويحية ودورها في الرفاهية النفسية لاى الطلبة من ذوي الإعاقة.

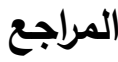

أولاً: المراجع العربية

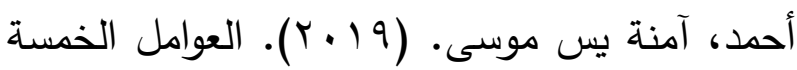

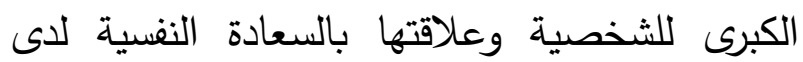
عينة من الطلاب المعاقين بجامعة الفاشر بمدينة الفاشر ولاية شمال دارفور • مجلة الدراسات العليا، كلية الدراسات العليا، جامعة النيلين، سا دال (.0)، $.14-79$

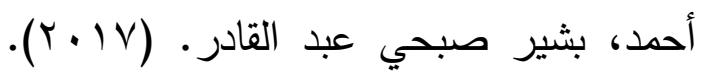

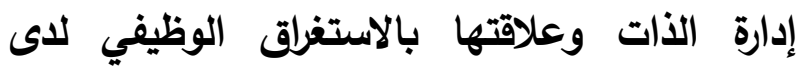
العاملين في المؤسسات الحكومية وغير الحكومية

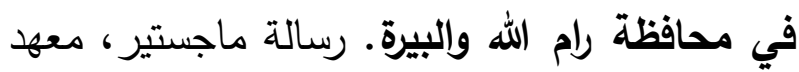
التتمية المستدامة، جامعة القدس.

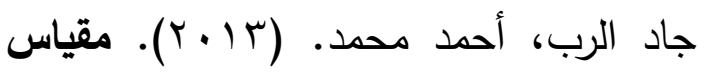
طيب الحياة النفسية. مكتبة الأنجلو المصرية، النها،

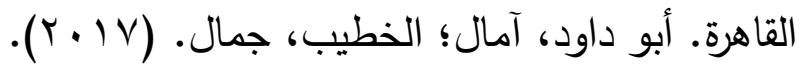
الرضا عن الحياة وعلاقته بكل من مهارات تقرير المصير والأمل لدى المراهقين ذوي الإعاقة

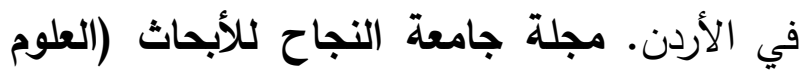

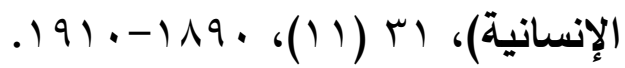




$$
\text { أحلام علي أحمد الزهراني و مجدة السيد علي الكثكي }
$$

من المعاقين سمعياً. مجلة الدراسات العربية في

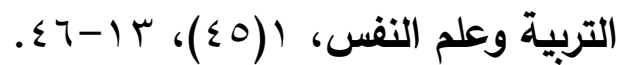

محمد، محمد عبد العزيز • (T ( • ( الإسهام

النسبي لكل من السلوك الاجتماعي الإيجابي وهوية الانا في التتبؤ بجودة الحياة لدى ذوي الإعاقة الإيلاعي السمعية. مجلة بحوث عربية في مجالات التربية

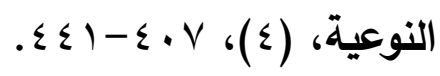

محمود، هويدة حنفي. (Y (Y. (Y). الصلابة

النفسية وإدارة الذات وعلاقتها بالصحة النفسية والنجاح الأكاديمي في ضوه بعض المتغيرات لدى

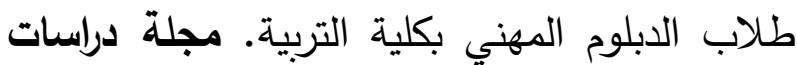

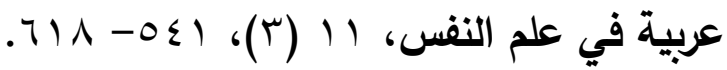

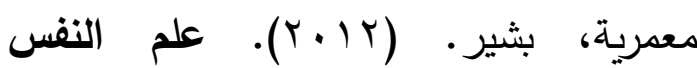
الإيجابي- اتجاه جديد لاراسة القوى والفضائل الإنسانية. الجزائر، دار الخلدونية.

مفلح، فدوى شوقي؛ حريز، نورا محمد. (Y..V) البداية ناشرون وموزعون، عمان. هادي، ابتسام راضي. (9 (ب). الابداع الانفعالي وعلاقته بالرفاهية النفسية لدى تدريسي كلية

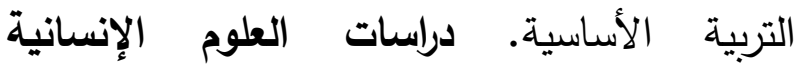

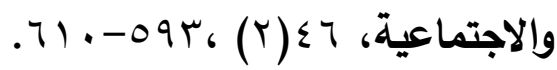

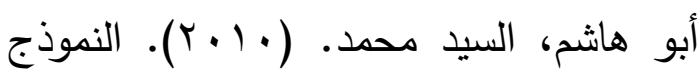
البنائي للعلاقات بين السعادة النفسية والعوامل
النفية للشباب الجامعي، كلية التربية، جامعة عين شمس، مجلة الإرشاد النفسي، (דب)، $.79 \leqslant$ العجاج، اعتزاز يوسف. (10 • ب). إدارة الذات

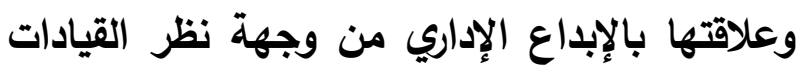

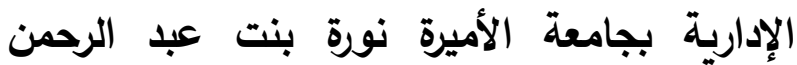
بالرياض. رسالة ماجستير، قسم العلوم الإدارية، كلية العلوم الاجتماعية والإدارية، جامعة نايف العربية

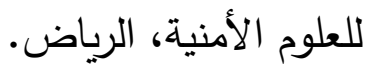

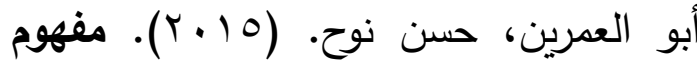
الأت واستراتيجيات التواصل الاجتماعي لاى الطلبة الصم في ضوء التقدم التقني. رسالة ماجستير، كلية التربية، الجامعة الإسلامية، غزة.

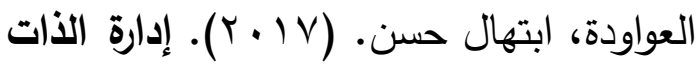
وعلاقتها بالإداء الوظيفي لدى العاملين بالمؤسسات الحكومية وغير الحكومية في محافظة الخليل. رسالة ماجستير غير منشورة، جامعة القدس،

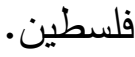
العوراني، عمر إسماعيل حمزة. (10 ب. (1). مفهوم الذات والرضا عن الحياة لاى الطلبة ذوي الإعاقة البصرية وذوي الإعاقة السمعية في الجامعة الأردنية. رسالة دكتوراه، كلية الدراسات العليا، الجامعة الأردنية، الأردن.

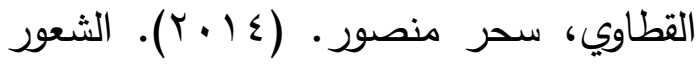
بالسعادة النفسية وعلاقته ببعض المتغيرات لدى عينة 


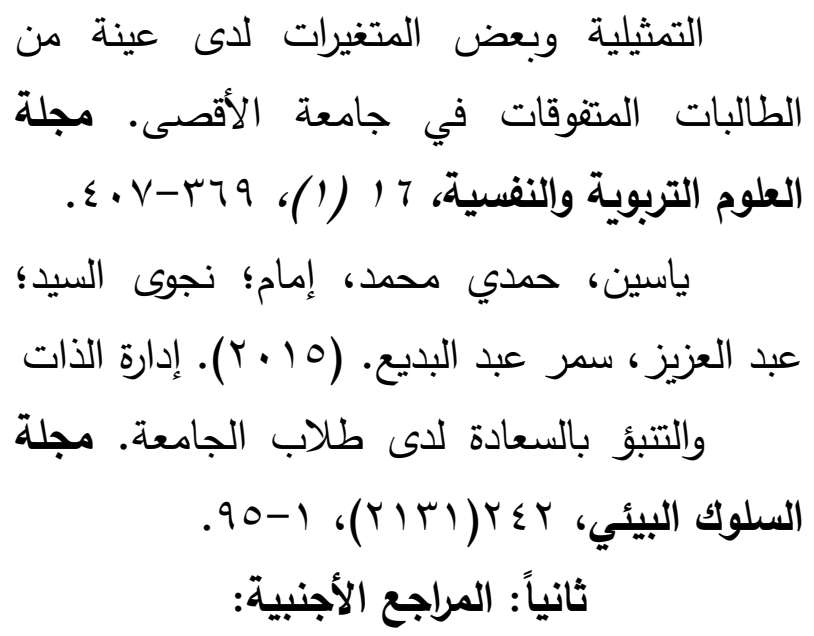

Awasthi, P., Chauhan, R., \& Verma, S. (2016). Subjective well-being of physically disabled and normal students. Indian Journal of Health \&Wellbeing, 7(6), 579584.

Diener, E., Semmons, R., Larsen, R., Griffin,S. (1984). The Satisfaction

with life Scale. Journal of Personality Assessment. 49, 71-75.

Johansson, et al., (2007). Confidence and happiness adults and self

management. Journal of sport psychology, 129 (6), 796- 797.

Maaulot, N., Faisal, R., Ishak, N., Lani, N \&Ing,O. (2015). Psychological

well- being among gifted students at the national gifted center in Malysia, Asian Conference on Psychology and Behavioral Sciences Official Conference Proceedings, 2-9.

Neini, H., Nevgi, A., Virtanen, p. (2003). Towards self- regulation in web- based learning. Journal of Educational Media,28(1),49- 71.

Nel, L.(2011). The Psychological Experiences of Master`s Degree-

Students in Professional Psychology

Programmes: An

Disabilities, 32(2), 390-400.

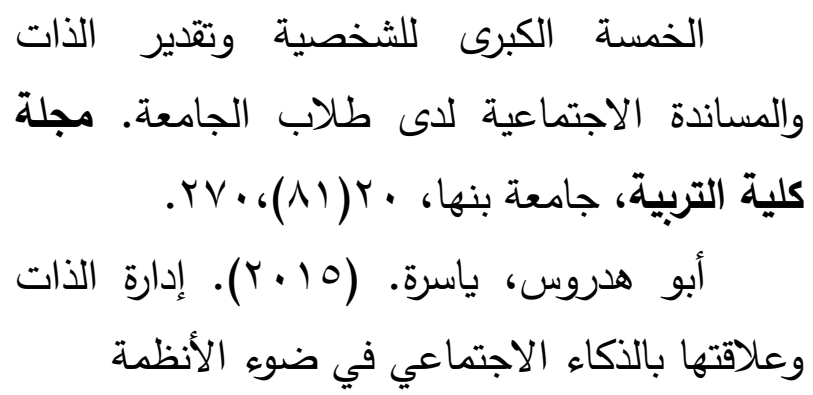

Interpretative. Phenomenological Analysis ,Ph D. Dissertation, Capella University.

Ryff, C., Magee, W., Kling, K.,\& Wing, E. (1999). Forging Macro-Micro

Linkages in The Study of Psychological Well-being. In C.Ryff \&V.

Marshall (Eds) The Self and Society in Aging Processes,

(PP247-278)New York: Springer

Publishing Company

Ryff, C \&

Singer, B. (2008). Know Thyself and Become What You Are: A Eudaimonic Approach To Psychological Well- Being. Journal of Happiness Studies, 9 ,1339.

Samsari, E. P., \& Soulis, S. G. (2019). Problem Solving and Resilience

Self- Efficacy as Factors of Subjective WellBeing in Greek Individuals with and without Physical Disabilities. International Journal of Special Education, 33(4) 938-953 Sandjojo, J., Zedlitz, A. M. E. E., Gebhardt, W. A., Hoekman, J., den

Haan, J. A., \& Evers, A. W. M. (2019). Effects of a Self-Management Training for People with Intellectual Disabilities. Journal of Applied Research in Intellectual 


$$
\text { أحلام علي أحمد الزهراني و مجدة السيد علي الكشكي }
$$

\title{
Psychological Well-being and its relationship to self-management among a sample of students with disabilities at King Abdulaziz University in Jeddah
}

\author{
Ahlam Ali Ahmad Alzahrani \\ Psychology \\ King Abdulaziz University- Jeddah \\ Department of Psychology \\ Faculty of Arts \& Humanities
}

\author{
Professor. Mogeda Elsayed Aly Elkeshky \\ King Abdulaziz University- Assiut University \\ Department of Psychology
}

Faculty of Arts \& Humanities

\begin{abstract}
. the study aimed at identify the psychological well-being its relationship to self-management among a sample of students with disabilities at King Abdulaziz University in Jeddah. the study sample consisted of (47) students, the researcher used the descriptive method, The researcher used the following tools: Psychological Well-being scale (preparation by Ryff, 2007), (translated by Elkeshky), and Selfmanagement scale (preparation by Hasan, 2010). The results indicated to the following: There is statistically significant relationship between the psychological well-being and self-management of disabled students, No statistically significant differences in the psychological well-being and selfmanagement due to the type of disability, and the level of the psychological well-being and selfmanagement are high. Some recommendations were forwarded to the concerned entities
\end{abstract}

Keywords: Psychological well-being, self-management, students with disabilities. 